\author{
螺芳基钲钛矿太阳能电池空穴传输材料研究进展 \\ 刘庆琳 $a$ 任保轶 $*, a$ 孙亚光 ${ }^{*}, a$ 解令海 $b$ 黄维 $b$ \\ ( ${ }^{a}$ 沈阳化工大学 理学院 辽宁省无机分子基化学重点实验室 沈阳 110142) \\ ( $b$ 南京邮电大学 省部共建有机电子与信息显示国家重点实验室 南京 210023)
}

\begin{abstract}
摘要 近 10 年, 第三代光电能源转换技术钙铁矿太阳能电池(PSCs)正迅速崛起. 基于有机-无机杂化钙钛矿材料的本 征半导体特性以及 PSCs 平面多层器件架构特点, 采用有机小分子空穴传输材料(HTMs)作为 PSCs 的 p-型层, 不仅实现 了 PSCs 器件的全固态化, 且大幅提升了器件效率及稳定性. 以当前通用的标准空穴传输材料 spiro-OMeTAD $\left(2,2^{\prime}, 7,7^{\prime}-\right.$ 四 [ $N, N$-二 (4-甲氧基苯基)氨基]- $9,9^{\prime}$-螺二荡)为模板, 研究人员开展了众多结构剖析和改进工作. 分子 spiro-OMeTAD 中, 三维螺二夰 (SBF)核能以较小的空间集成更多的空穴传输单元; 而芳胺优异的 $\mathrm{p}$-型特性, 使其成为高效的电活性单 元. 经典螺芳核 SBF 制备成本高, 可修饰位置单一; 因此, 基于 spiro-OMeTAD 的结构改进主要围绕芳胺单元的修饰开 展. 随着 HTMs 分子设计以及合成方法学的进展, 近 5 年来, 一系列低成本、高性能的类 SBF 螺芳基单元逐渐兴起, 并 迅速进入空穴传输材料领域, 如: 螺[荡-9,9'-氧杂葱]、螺吅啶、螺硫杂葱等. 螺芳基核结构的日益丰富, 大大拓展了 HTMs 分子的设计空间, 从而推动了 PSCs 效率和稳定性的不断提升. 因此, 本综述聚焦含螺芳烃骨架的 HTMs 分子, 根据其器件性能表现，分析高性能材料的结构要素. 按照螺芳烃核结构对高性能 HTMs 进行分类归纳, 总结了结构设 计思路和构效关系. 期望通过较为全面的评述, 为 HTMs 分子构建提供可参考的策略, 从而推动 PSCs 继续向高效率、 长寿命的实用化方向发展.
\end{abstract}

关键词＼cjkstart钻钑矿太阳能电池; 空穴传输材料; 螺环芳烃; 构效关系

\title{
Research Progress of Hole Transport Materials Based on Spiro Aromatic-Skeleton in Perovskite Solar Cells
}

\author{
Qing-Lin Liu $^{a} \quad$ Bao-Yi Ren*,a Ya-Guang Sun*,a Ling-Hai Xie ${ }^{b} \quad$ Wei Huang $^{b}$ \\ ( ${ }^{a}$ Key Laboratory of Inorganic Molecule-Based Chemistry of Liaoning Province, College of Science, \\ Shenyang University of Chemical Technology, Shenyang 110142, China) \\ ( ${ }^{b}$ State Key Laboratory of Organic Electronics and Information Displays, Nanjing University of \\ Posts \& Telecommunications, Nanjing 210023, China)
}

\begin{abstract}
The third-generation energy electro-optical technology, perovskite solar cells (PSCs), have risen fast over the past decade. In view of the characteristic of intrinsic-semiconductor of organic-inorganic hybrid perovskite materials, as well as the multilayer planar architecture of PSC devices, the hole transport materials (HTMs) based on organic small molecules were introduced PSCs to make up of p-type layer, by which not only full-solid state PSCs were established, but also the highly efficient and stable PSC devices were attained. Currently, spiro-OMeTAD (2,2',7,7'-tetrakis[N,N-di(4-methoxyphenyl)amino]-9,9'-spirobifluorene) is still used as an universal benchmark material in the hole-transporting layer of PSCs, meanwhile the researches have make great effort to analyze and to improve the spiro-OMeTAD. For the prevailing molecule, the three-dimensional core of spirofluorene (SBF) offers a platform to integrate more hole-transporting units with less occupied space, and arylamine groups act as high electroactivity units due to their excellent p-type property. However, the classical SBF core has two major drawbacks: expensive preparation cost and monotonous modification positions, therefore the improvement orientation of spiro-OMeTAD is focused on the arylamine moieties. Along with the developments of molecular design of HTMs and corresponding synthetic methodology, a series of SBF-like aromatic-skeletons have been springing up and stepping into the field of HTMs in recent five years, e.g. spiro[fluorene-9, $9^{\prime}$-xanthene], spiroacridine, spirothioxanthene and so on. These advancements expand the design space of HTM molecules, and enhance the efficiency and stability of PSCs. In consequence, we put eyes on the HTMs containing spiro aromatic-skeleton, and seek the structure elements of highly efficient materials. In this review, the high performance HTMs have been classified and summarized according to the type of spiro structure, further, their design solution and structure-performance relationship have also been refined. It is expected that the summarization and condensation would provide valuable strategies for HTMs design and promote the devel-
\end{abstract}

*E-mail: renbaoyi@syuct.edu.cn; sunyaguang@syuct.edu.cn

Received June 7, 2021; published July 12, 2021.

Project supported by the Science Research Plan of Shenyang University of Chemical Technology (XXLJ2019006), the Soft-Science Research Plan of Yingkou City (2020JH2/0100017), and the Open Research Project of Key Laboratory for Organic Electronics and Information Displays.

项目受沈阳化工大学科学研究计划(XXLJ2019006)、营口市软科学研究计划(2020JH2/0100017)和江苏省有机电子与信息显示重点实验室一省部共建 国家重点实验室培育基地开放研究基金资助. 
opment of highly efficient and long-life PSCs towards practical application.

Keywords perovskite solar cell; hole transport material; spiro aromatic-skeleton; structure-performance relationship

\section{1 引言}

随着传统化石能源日益枯竭及其使用带来的严重 环境问题，学界及产业界迫切地将目光投向清洁、可再 生能源的开发与高效利用 ${ }^{[1]}$. 当前, 太阳能光伏作为可 再生能源利用的主导性技术, 是解决能源和环境问题的 重要途径之一 ${ }^{[2]}$. 第一代硅基太阳能电池虽已商品化应 用, 但其能量转换效率 (power conversion efficiency, $\mathrm{PCE}$ )逐渐接近理论极限; 同时, 单晶/多晶硅存在制备 工艺条件苛刻, 材料质重刚性, 以及光刻蚀严重等问题. 因此, 基于有机聚合物/小分子的第二代有机太阳能电 池和基于钙钛矿材料的第三代光伏技术, 在近 10 年得 到了充分关注, 并取得快速进步. 自 2009 年发现有机无机杂化钙钛矿材料的光伏应用潜力以来, 通过对其组 成、结构、尺度、器件架构的优化及电荷传输材料的研 发, 器件效率得以快速提升, 从最初的 $3.8 \%{ }^{[3]}$ 达到最新 报道的 $25.5 \%$ 记录效率 ${ }^{[4]}$ (标志性 PCE 突破如图 1 所示), 实用化前景日益显现.

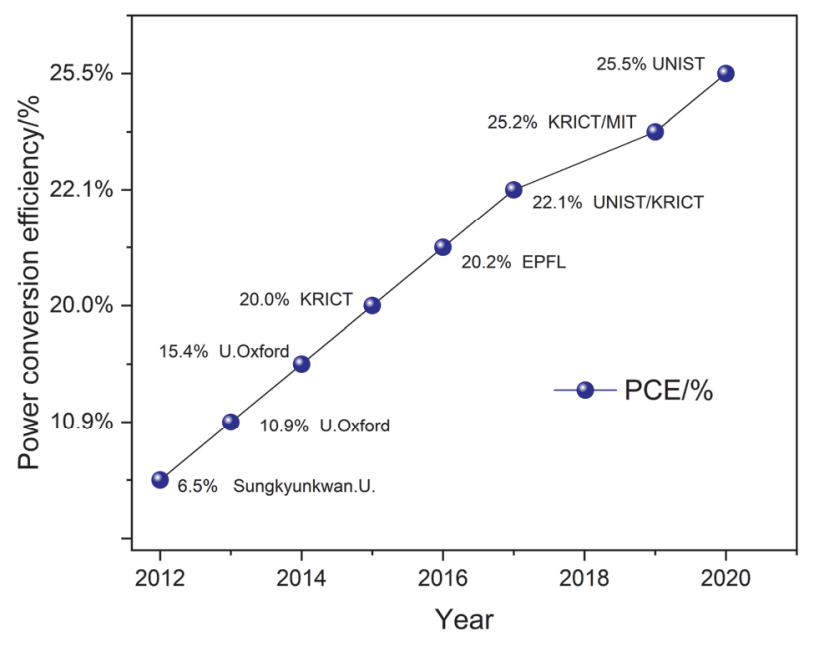

图 1 标志性钲钛矿太阳能电池效率进展示意 ${ }^{[4-11]}$

Figure 1 The PCEs progresses of perovskite solar cells ${ }^{[4-11]}$ 钙钛矿太阳能电池(perovskite solar cells, PSCs)是利 用钙钛矿型有机金属卤化物半导体作为光电转换材料 的太阳能电池 ${ }^{[12]}$. 1926年, Goldschmidt ${ }^{[13]}$ 确认了有机-无 机杂化钙钛矿为八面体或立方体的 $\mathrm{AMX}_{3}$ 结构 (与俄罗 斯矿物学家 Lev Perovsky 发现的钛酸钙 $\mathrm{CaTiO}_{3}$ 晶体结 构相同, 因此称为 perovskite ${ }^{[14-15]}$, 如图 2 所示: $\mathrm{A}$ 代表 $\mathrm{CH}_{3} \mathrm{NH}_{3}{ }^{+}$(甲胺, methylamine ion, $\mathrm{MA}$ ), $\mathrm{NH}_{2} \mathrm{CH}=\mathrm{NH}_{2}{ }^{+}$ (甲脒, formamidine ion, FA)等一价有机阳离子, $\mathrm{M}$ 代表 $\mathrm{Pb}^{2+}, \mathrm{Sn}^{2+}$ 等二价金属阳离子, $\mathrm{X}$ 代表 $\mathrm{I}^{-}, \mathrm{Cl}^{-}$和 $\mathrm{Br}^{-}$等卤 素阴离子. $\mathrm{A}$ 离子位于立方晶胞的角顶, 被 12 个 $\mathrm{X}$ 离子 包围成配位八面体, 配位数为 $12, \mathrm{M}$ 离子位于立方晶胞 的中心, 被 6 个 $\mathrm{X}$ 离子包围成配位立方八面体, 配位数 为 6 ; 因一价阳离子和卤素阴离子半径相近, 共同构成 立方密堆积.

钲钛矿半导体材料具有高消光系数、长激子扩散长 度、弱激子结合能、高电子/空穴迁移率及可调控的带隙 和溶液加工等优点. 这是由于在 $\mathrm{AMX}_{3}$ 结构中, 电子和 空穴在无机骨架上的势能较小, 有机部分促使了紧密的 堆积方式, 使载流子得以有效的输运 ${ }^{[16]}$. 因此, 在日光 辐射下, 有机-无机杂化钙钛矿薄膜内能够快速完成激 子产生、电荷分离和载流子传输等过程, 高效地将光能 转化为电能 ${ }^{[17-18]}$ (图 2).

鉴于有机-无机杂化钙钛矿材料的本征半导体特性, 钲钛矿电池主要采用平面异质结架构, 器件特点是结构 简单、稳定性好、光电转换效率高. 平面异质结器件包 括: n-i-p 正型结构(即电子传输层-钻钛矿层-空穴传输层 结构 ${ }^{[19-20]}$ 和 $\mathrm{p}-\mathrm{i}-\mathrm{n}$ 反型结构(空穴传输层-钙钛矿层-电子 传输层的结构 ${ }^{[21-23]}$. n-i-p 型是目前最典型的钙钛矿电 池结构, 优点是能有效地抑制回滞现象, 减少电荷复合, 从而提升器件效率和稳定性 ${ }^{[24]}$.
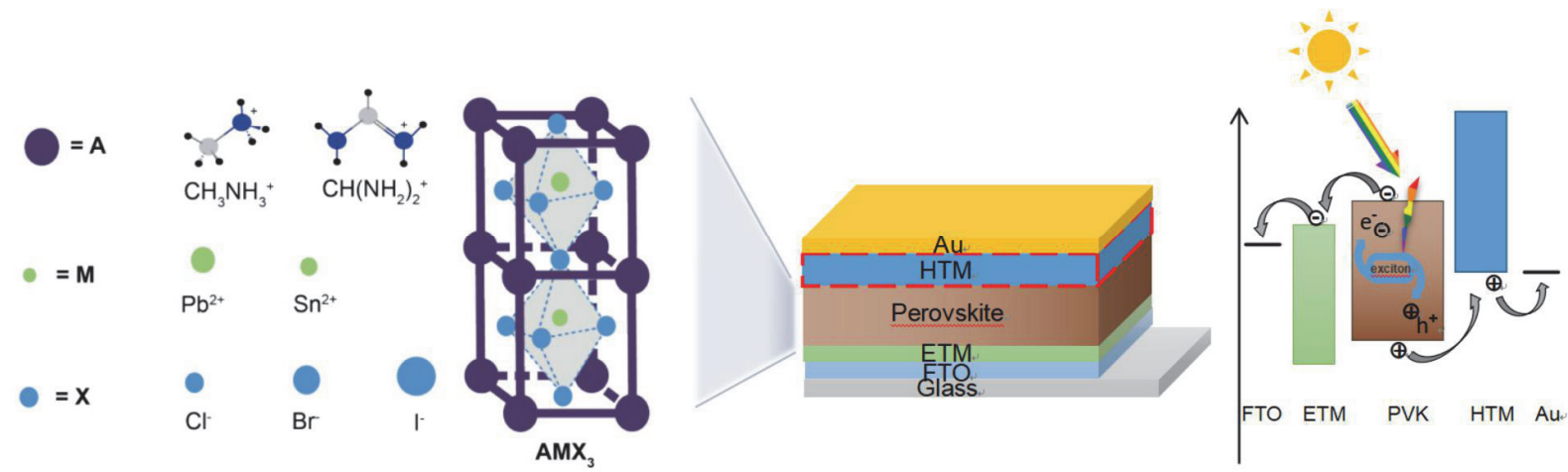

图 2 有机-无机杂化钲铁矿晶体结构和器件结构及工作原理示意图 ${ }^{[25]}$

Figure 2 Schematic diagram of crystal structure of organic-inorganic hybrid perovskite, PSC device architecture and its working principle ${ }^{[25]}$ 
多层平面异质结电池器件架构中, 空穴传输层是不 可或缺的组成部分. 目前, 空穴传输材料(hole transport materials, HTMs)主要有三类, 即: 有机小分子、共轭聚 合物和无机 p-型半导体材料. 2012 年 Kim 等 ${ }^{[26]}$ 首次将有 机小分子 spiro-OMeTAD(图 3)作为空穴传输材料用于钙 钛矿电池器件中, 实现了活性层的全固态化, 大幅提升 了器件效率和稳定性, 进而开启了有机小分子空穴传输 材料的研究热潮. 此前, 无机空穴传输材料虽可形成全 固态器件, 并在稳定性、空穴迁移率和材料成本上占据 一定优势, 但相应器件制备工艺复杂, 活性层形貌和界 面稳定性表现不佳. 共轭聚合物作为空穴传输材料的主 要问题是: 合成条件苛刻、成本高及批次质量差异大. 相比之下, 具有明确结构的有机小分子空穴传输材料优 点是: 能级易调控, 能更好地与钙钛矿及电极材料匹配, 合成方法简洁, 可稳定控制批次质量, 从而确保器件制 备工艺、各项性能指标具有良好的重复性 ${ }^{[27-29]}$. 基于有 机小分子材料的上述优势, 以及螺环体系独特的三维正 交结构, spiro-OMeTAD 是当前考量钙钛矿太阳能电池 性能的首选和基准空穴传输材料[30-31].

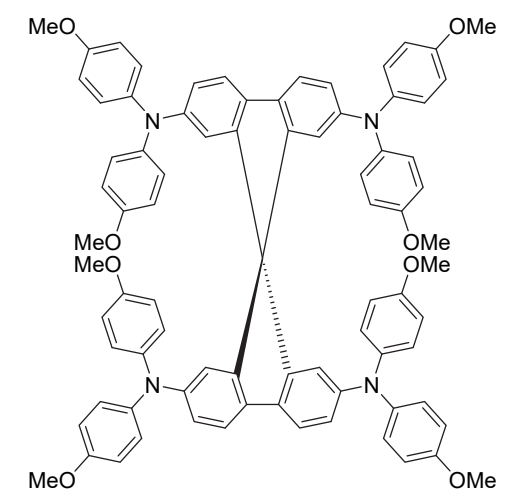

图 3 spiro-OMeTAD 的结构式

Figure 3 The structure of spiro-OMeTAD

近期, 研究人员就基于螺芳烃体系的小分子空穴传 输材料开展了众多系统性的研究工作, 包括: 改造螺芳 烃骨架结构, 调控分子聚集行为; 修饰空穴传输功能单 元, 优化各层材料间的能级匹配程度, 促进电荷输运; 引入疏水性原子/基团, 提升活性层间界面稳定性 ${ }^{[32]}$. 研究进展充分表明: 以三维螺芳基模块为空穴传输材料 构建平台, 经合理的能带工程和晶体工程设计, 衍生、 丰富结构多样的小分子空穴传输材料库, 能够获得迁移 率、稳定性和制备成本等综合优势突出的高性能分子, 进而加速钙钛矿电池商品化的步伐.

因此, 本综述以有机-无机杂化钙钛矿材料、光伏器 件结构及工作原理为背景, 聚焦螺芳基核骨架这一共性 特征, 篮选、剖析高性能空穴传输材料的结构要素, 着 重介绍近 5 年螺芳基钙钛矿太阳能电池空穴传输材料的 研究进展. 力图通过比较、总结, 抽提出分子设计与电 荷输运性能、电池能量转换效率间的构效关系. 期望通 过较为系统的归纳和评述, 为领域内研究者提供可参考
的分子设计策略，推进钙钛矿太阳能电池向高效、长寿 命的实用化方向发展.

\section{2 基准空穴传输材料: spiro-OMeTAD}

spiro-OMeTAD 是在螺二芴核上构建的正交四元芳 香叔胺分子(图 3), 叔胺单元作为空穴传输功能部分; 而刚性螺环核结构使其在应用中，能保持空穴传输层的 热和形貌稳定性 ${ }^{[33]}$ 及三维载流子输运性能, 从而减少 激子复合, 确保电池效率和寿命. 目前, spiro-OMeTAD 是钙钛矿太阳能电池中的基准空穴传输材料.

螺二芴的一个重要特征是螺原子两侧严格 “十字交 叉” 的 $\pi$ 体系. 三维正交构型有效抑制了分子间相互作 用， $\pi-\pi$ 堆积被弱化 ${ }^{[34]}$. 同时，中心 $\mathrm{sp}^{3}$ 杂化碳原子的刚 性可诱导非晶态纠缠, 抑制薄膜中分子再结晶 ${ }^{[35]}$, 形成 较为稳定、均一的晶界. 以二苯胺单元对称修饰 SBF 的 $2,2^{\prime}, 7,7^{\prime}$-位时，材料在三维空间具有较好的电荷传输性 能 ${ }^{[36-37]}$. 因此, spiro-OMeTAD 作为基准材料的同时, 也 是空穴传输小分子设计、开发的重要参考模板.

基于此，优化空穴传输性能的工作主要集中在以下 三方面: (1) 改造空穴传输功能单元及变换取代位置, 调控分子的最高占据分子轨道(highest occupied molecular orbital, HOMO)能级; (2) 改进中心螺环芳烃骨架, 继承、加强螺芳基分子薄膜的均一性和稳定性，提升空 穴传输层的导电性; (3) 发展新的合成方法, 降低材料 制备成本 ${ }^{[38]}$. 以下，围绕螺芳烃核骨架这一中心，分类 介绍、讨论各类小分子螺芳基空穴传输材料的结构设 计、本征光电性质和相应钙钛矿太阳能电池效率的进展.

\section{3 螺二芴基空穴传输材料}

螺二芴(spirobifluorene, SBF)核凭借上述特点, 在空 穴传输材料设计中被充分关注，研究人员通过调整芳胺 结构、引入烷基侧链、位置异构和氟化等策略, 获得了 一系列性能堪比 spiro-OMeTAD 的新分子. 以下，按 $\mathrm{SBF}$ 的合成方法、分子设计及电池性能脉络, 介绍基于 SBF 核空穴传输材料的研究进展.

\section{1 螺二芴的合成}

SBF 的合成最早可追溯至 1930 年, 且该路线延续 应用至今 ${ }^{[39-41]}$. 如图 4所示, 9-芴酮与 2-溴联苯的金属有 机试剂(常用镁试剂或锂试剂), 发生亲核加成得到芳基 叔醇中间体，再经质子酸催化 Friedel-Crafts 反应，闭

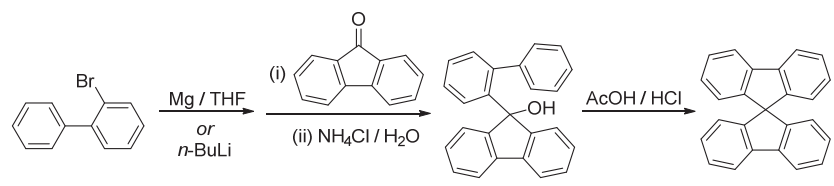

图 4 螺二芴的合成路线 ${ }^{[40]}$

Figure 4 The synthesis route of spirobifluorene ${ }^{[40]}$ 
环构成以 $\mathrm{sp}^{3}$ 杂化碳为中心的螺双芴结构.

电活性结构引入 $\mathrm{SBF}$ 核上主要依赖 $\mathrm{C}-\mathrm{N} 、 \mathrm{C}-\mathrm{C}$ 等钯催化交叉偶联反应, 此时需要使用 SBF 的卤代物为 偶联组分之一. 因此, 基于亲电卤代的定位规律, SBF 上最便利的偶联位置是 $2,2^{\prime}, 7,7^{\prime}$-位.

\subsection{SBF 基空穴传输材料}

螺芳烃能够以尽可能小的几何空间集成更多的电 活性单元, 这是 SBF 成为空穴传输材料核结构的重要原 因之一. 图 5 列出了近期基于 SBF 的高性能空穴传输材

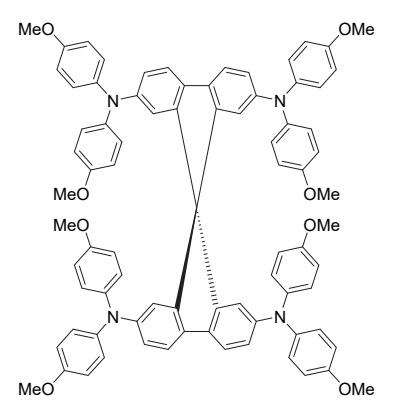

$p p$-spiro-OMeTAD
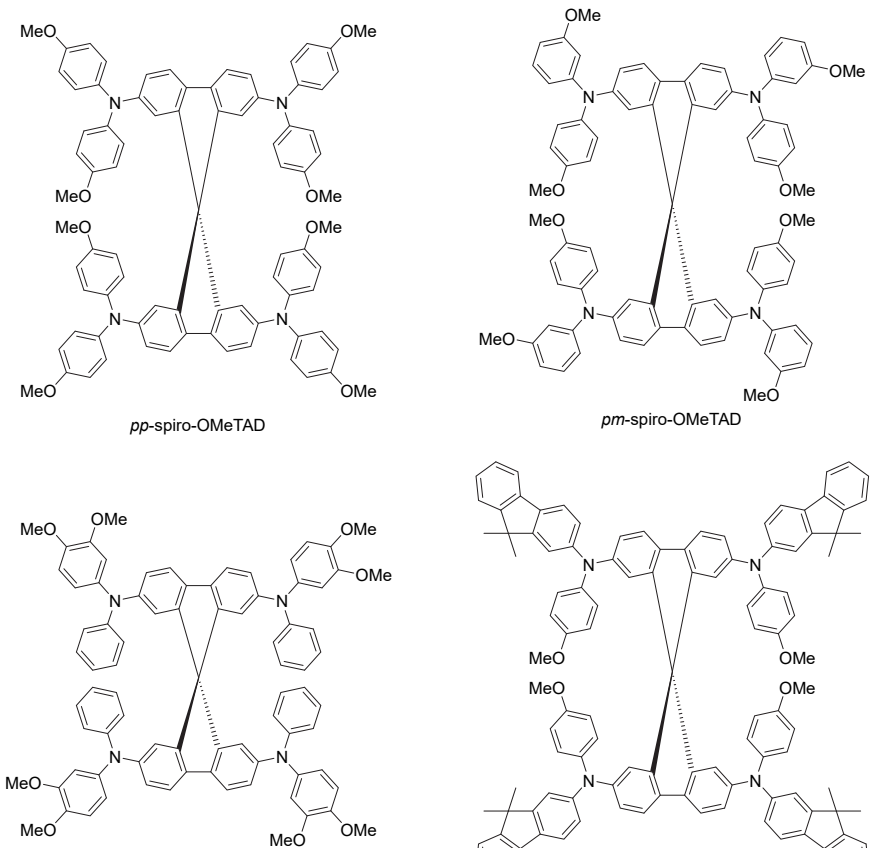

3,4-spiro-OMETAD

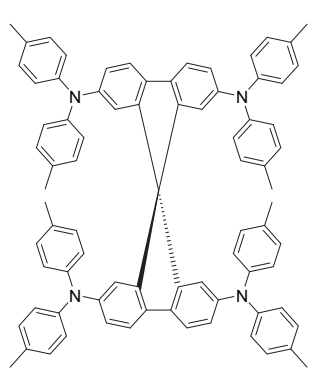

spiro-MeTAD1 (sprio-TTB)

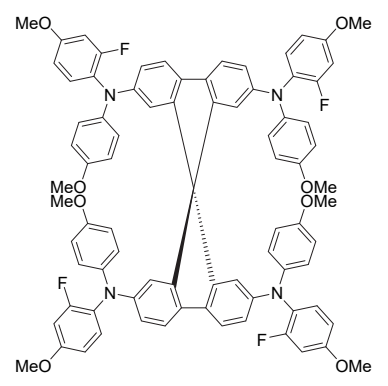

spiro-oF

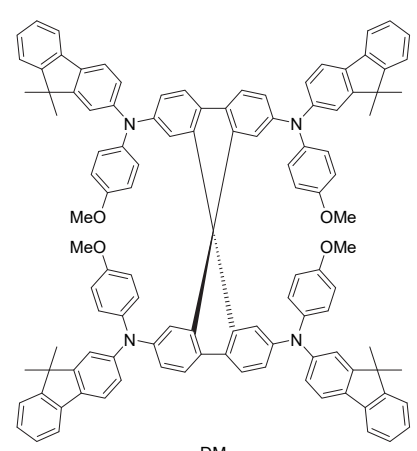

DM

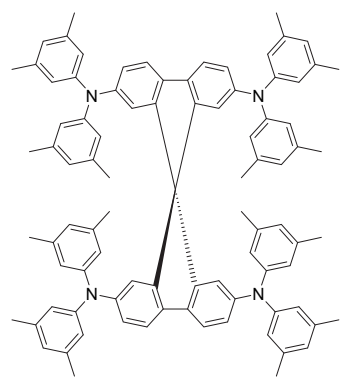

spiro-MeTAD2

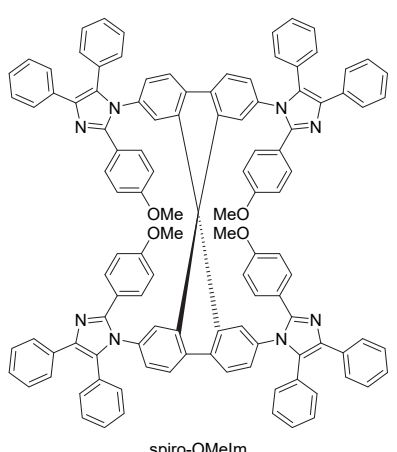

料的分子结构. 参照 spiro-OMeTAD, Seok 等[42]制备了 单个苯环上甲氧基邻位、间位取代的一对位置异构体: $p m$-spiro-OMeTAD 和 $p o$-spiro-OMeTAD. 甲氧基的位置 变化首先改变了材料的 $\mathrm{HOMO}$ 能级, 与 spiro-OMeTAD(即 $p p$-spiro-OMeTAD)相比, $p m$-spiroOMeTAD 的 HOMO 能级降低了 $0.09 \mathrm{eV}$, 归因于间位取 代后甲氧基的供电子效应对分子共轭系统的稳定作用; 而 $p o$-spiro-OMeTAD 的 LUMO 能级提高了 $0.10 \mathrm{eV}$, 主 要是由于邻位甲氧基的位阻效应, 使苯基与螺环间的二 面角增加, 减少了分子的有效共轭. 器件性能研究显示,
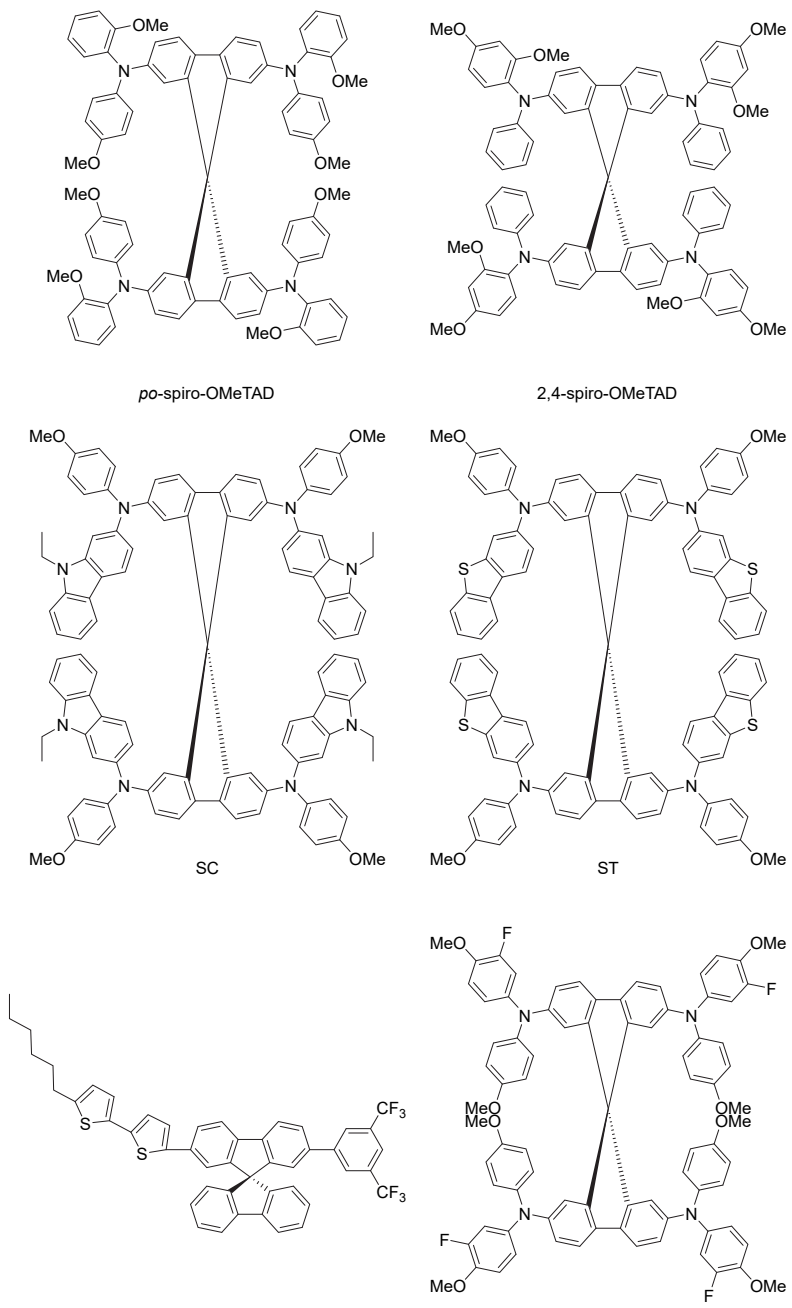

CF-SP-BTh

spiro- $m F$

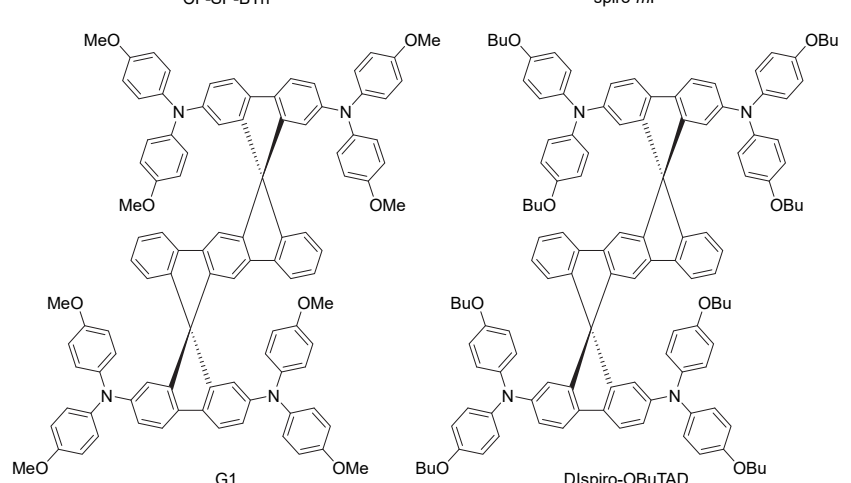



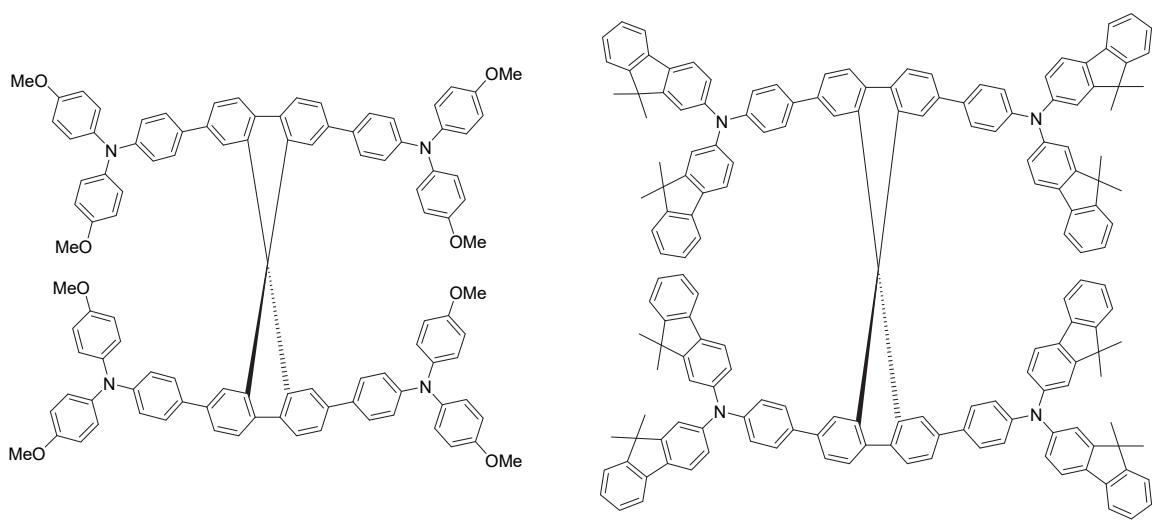

spiro-F2

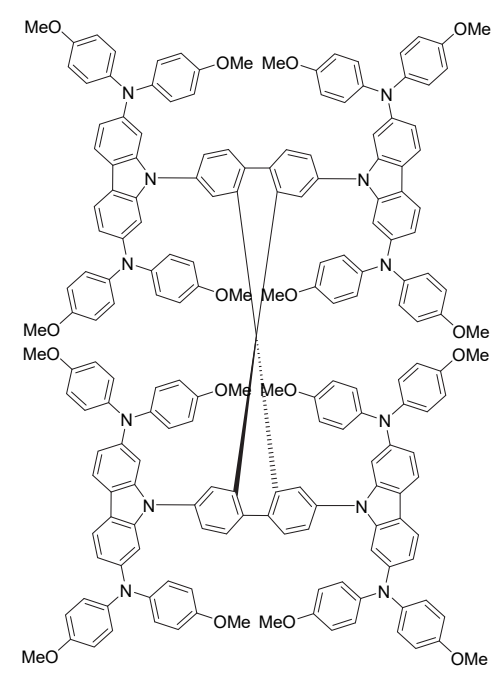

spiro-F3

图 5 螺二芴为中心核的空穴传输材料

Figure 5 Hole transport materials with spirofluorene core in perovskite solar cells

基于甲氧基邻位 $p o$-spiro-OMeTAD 的电池 PCE 达到 $16.7 \%$, 优于 $p m$-spiro-OMeTAD 和 $p p$-spiro-OMeTAD 基 器件的 $13.9 \%$ 和 $14.9 \%$, 表明协同优化分子的能级和位 阻作用, 能够进一步提升 spiro-OMeTAD 类空穴传输材 料的性能. 类似地, Zhang 等 ${ }^{[43]}$ 合成了 2,4-spiroOMeTAD 和 3,4-spiro-OMeTAD, 通过将甲氧基集中到 二苯胺的单侧苯环, 同样是含邻位取代的 2,4-spiroOMeTAD 材料, 电池 PCE 相对 spiro-OMeTAD 基电池的 $15.0 \%$, 提升至 $17.2 \%$. 该结果再次证明了邻位甲氧基取 代的空穴传输材料对钙铁矿太阳能电池有促进作用.

芴单元的刚性平面结构及宽带隙特点, 可提升有机 半导体的光、热稳定性及载流子输运能力. Jeon 等 ${ }^{[44]}$ 设 计了含有芴基芳胺结构的空穴传输材料, 合成的 DM 分 子 HOMO 能级为 $-5.27 \mathrm{eV}$, 较 spiro-OMeTAD 降低了 $0.05 \mathrm{eV}$, 带隙缩窄至 $2.91 \mathrm{eV}$, 玻璃化转变温度达到 $161{ }^{\circ} \mathrm{C}$. 基于 $\mathrm{DM}$ 电池的平均 $\mathrm{PCE}$ 为 $22.3 \%$, 高于 spiro-OMeTAD 对照器件的 $21.3 \%$. 同时, 认证的大面积 $\left(\approx 1 \mathrm{~cm}^{2}\right)$ 电池 $\mathrm{PCE}$ 达到 $20.9 \%$, 且 $60{ }^{\circ} \mathrm{C}$ 退火 $500 \mathrm{~h}$ 后, PCE 仍保持在初始性能的 95\%以上(图 6). DM 基器件的 高效率和长期稳定性, 表明了通过优化小分子空穴传输 材料提升电池 PCE 的潜力. Deng 等 ${ }^{[45]}$ 合成了与 DM 结 构相似的 $\mathrm{SC}$ 和 $\mathrm{ST}$, 采用 $N$-乙基咔唑和二苯并噻吩取代 $\mathrm{DM}$ 中的 4-甲氧基苯基和 9,9-二甲基- $9 H$-芴, $\mathrm{SC}$ 和 $\mathrm{ST}$ 的 HOMO 能级较 spiro-OMeTAD 分别下降 0.04 和 0.09 $\mathrm{eV}$. 在薄膜加工中发现, SC 具有良好的溶解性和较低的 结晶度; 形貌表征显示空穴传输层平滑、无针孔, 相应 电池 PCE 达到 21.76\%, 优于 spiro-OMeTAD 基器件的 $20.73 \%$. 未封装 SC 基器件在空气中 $30 \mathrm{~d}$ 稳定性测试后, PCE 仍保持初始值 $90 \%$ 以上. 该结果表明空穴传输层形 貌优化对䥻钛矿太阳能电池效率、稳定性的促进作
用 ${ }^{[46]}$. Sallenave 等[47]使用甲基替代 spiro-OMeTAD 中的 甲氧基, 合成了空穴传输分子 spiro-MeTAD1 和 spiroMeTAD2. 经甲基修饰后，因 HOMO 能级降低导致紫 外-可见吸收边轻微蓝移 $8 \mathrm{~nm}$, 更值得关注的是二者的 空穴迁移率较 spiro-OMeTAD 增高了 4 倍, 且热稳定性 增强. 但是, 相应电池的最高 PCE (17.2\%, 17.05\%)均低 于 spiro-OMeTAD 基器件(19.24\%). 该结果指出了钻钛 矿/空穴传输层界面性质相对空穴迁移率, 更加显著地 影响电池效率. Guo 等 ${ }^{[48]}$ 合成了结构与 spiro-MeTAD1 相同的分子 spiro-TTB, 材料的能级和空穴迁移率考察 结果与文献[47]基本一致. 但基于 $\mathrm{CH}_{3} \mathrm{NH}_{3} \mathrm{PbI}_{3}$ 和非掺 杂空穴传输层的钙铁矿电池性能测试显示：采用 spiro-TTB 的器件 PCE 达到 $18.83 \%$, 高于使用 spiro-

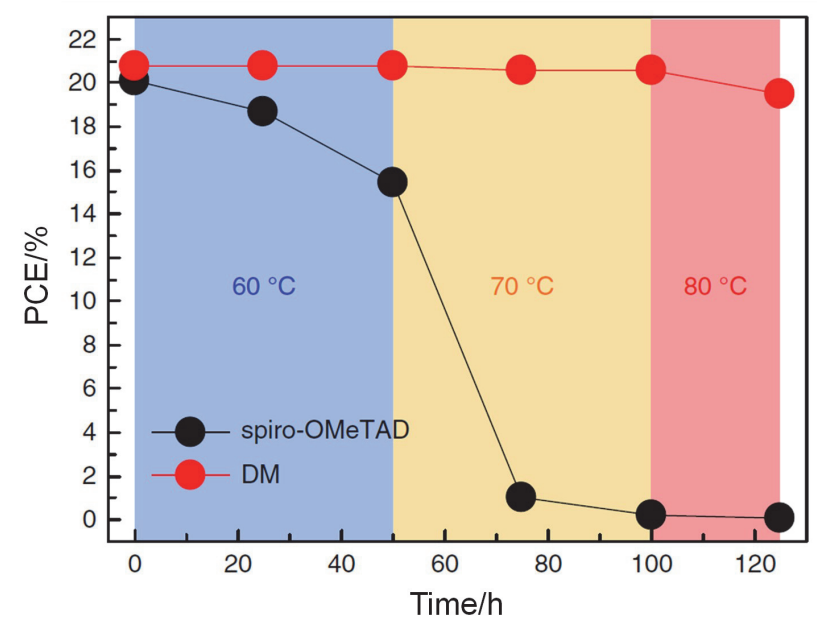

图 6 在不同温度 $60 、 70$ 和 $80{ }^{\circ} \mathrm{C}$ 的空气中(相对湿度约为 $25 \%$ )使用 DM 和 Spiro-OMeTAD 时, 器件的稳定性的变化 ${ }^{[4]}$

Figure 6 Stability of the devices stressed at different temperatures of 60,70 and $80{ }^{\circ} \mathrm{C}$ in air $(\approx 25 \% \mathrm{RH})$ with $\mathrm{DM}$ and spiro-OMeTAD ${ }^{[44]}$ 
OMeTAD 器件的 $15.92 \%$. 进一步分析表明: spiro-TTB 的疏水特征、均一的薄膜表面及 $\mathrm{CH}_{3} \mathrm{NH}_{3} \mathrm{PbI}_{3}$ 钙钛矿/ spiro-TTB 界面形貌, 与其良好的本征光电性质协同提 升了电池的开路电压(open-circuit voltage, $V_{\mathrm{oc}}$ )和填充因 子(fill factor, $F F$ ).

据报道, 在螺二芴核心单元中引入不同的给体或受 体基团, 能够获得三维分子构型、高透明度的 $\mathrm{HTMs}^{[41]}$. 鉴于空穴传输材料疏水性及其余钻钛矿光敏剂间相互 作用对活性层表界面形貌、电池效率的影响, Ameen 等[49]在 SBF 单侧引入 3,5-二(三氟甲基)苯和已基二噻吩, 得到空穴传输分子 CF-Sp-BTh. 结合掺杂氧化石墨烯对 提高 $\mathrm{CH}_{3} \mathrm{NH}_{3} \mathrm{PbI}_{3}$ 钙钛矿材料性能的辅助作用, CF-Sp-BTh 基电池的 PCE 达到 14.28\%. 氟化可显著改 善共轭材料的能级、疏水性和非共价相互作用, 因此, Jeong 等 ${ }^{[50]}$ 通过在 spiro-OMeTAD 的甲氧基苯基上引入 氟原子, 开发了两种空穴传输材料: spiro- $m \mathrm{~F}$ 和 spiro- $o \mathrm{~F}$. 间位氟化分子 spiro- $m \mathrm{~F}$ 的 HOMO 能级被深置于 -5.19 $\mathrm{eV}$, 疏水性较 spiro-OMeTAD 显著提高; 理论模拟揭示 了氟化分子与 $\mathrm{FAPbI}_{3}$ 表面的吸附作用显著增强. 基于 spiro- $m \mathrm{~F}$ 的 $\mathrm{FAPbI}_{3}$ 钙钛矿电池认证 PCE 高达 24.64\%, 潮湿环境下未封装电池工作 $500 \mathrm{~h}$ 后, PCE 仍保持在最 高效率的 $87 \%$. 并且, 大面积器件 $\left(1 \mathrm{~cm}^{2}\right)$ 的 PCE 也达到 了前所未有的 $22.31 \%$. 这一结果充分确证优化螺芳基 空穴传输材料理化性质, 为增强钙钛矿太阳能电池效率 和稳定性提供了巨大空间. Hajikhanmirzaei 等 ${ }^{[51]}$ 合成了 苯基咪唑功能化的 SBF 基空穴传输材料 spiro-OMeIm, 其 $\mathrm{HOMO}$ 能级 $(-5.13 \mathrm{eV})$ 与 $\left(\mathrm{FAPbI}_{3}\right)_{0.85}\left(\mathrm{MAPbBr}_{3}\right)_{0.15}$ 钙钛矿光吸收材料接近. 相应太阳能电池的 PCE 为 $11.64 \%$, 虽低于 spiro-OMeTAD 基器件的 $14.46 \%$, 但合
成成本较基准材料降低了 $80 \%$, 对发展更为廉价的钻钛 矿太阳能电池器件有很大的吸引力.

迄今为止研究的众多 HTMs 中, 以单螺环化合物为 实现高效 PSCs 最常用的 HTMs 中心核. 为了满足 HTMs 结构的设计多样化, 以进一步提高其功能和性能的需 要, 双螺环化合物成为人们研究的新热点. Gao 等 ${ }^{[52]}$ 合 成了一种基于二螺环的 G1, 证明了使用二螺环的 HTMs 用于高效 PSCs 的可行性. G1 具有良好的成膜性, 具有与钙钛矿更匹配的 HOMO 能级, 其器件 PCE 达到 了 $15.5 \%$. 基于此, 参考 spiro-OMeTAD 的结构, $\mathrm{Yu}$ 等 ${ }^{[53]}$ 设计并合成了一种新型二螺环化合物 Dispiro-OBuTAD, 获得了 $18.46 \%$ 的高 PCE 并证明了二螺环中心核是开发 高性能 PSCs 的优良 HTMs 的一种很有前途的设计原则.

除分子设计、合成实践和器件性能验证外, 理论计 算工作也关注到 spiro-OMeTAD 类材料. 以 spiro-OMeTAD 为参照物, $\mathrm{Chi}$ 等 ${ }^{[54]}$ 设计了苯、9,9'-二甲 基芴和二苯氨基咔唑基团延展电活性单元共轭结构的 分子: spiro-F1、spiro-F2 和 spiro-F3. 依据第一性原理计 算结果表明： spiro-F1、spiro-F2 和 spiro-F3 相比于 spiro-OMeTAD 具有更低且更匹配的 HOMO 能级, 可使 电池获得更高的 $V_{\mathrm{oc}}$. 此外, spiro-F1 $\left(1.75 \times 10^{-2}\right.$ $\left.\mathrm{cm}^{2} \cdot \mathrm{V}^{-1} \cdot \mathrm{s}^{-1}\right)$ 和 spiro-F3 $\left(7.59 \times 10^{-3} \mathrm{~cm}^{2} \cdot \mathrm{V}^{-1} \cdot \mathrm{s}^{-1}\right)$ 的空穴 迁移率分别是 spiro-OMeTAD $\left(5.65 \times 10^{-3} \mathrm{~cm}^{2} \cdot \mathrm{V}^{-1} \cdot \mathrm{s}^{-1}\right)$ 的 3.1 倍和 1.4 倍. 单分子 spiro-F3 的稳定性虽略低于 spiro-OMeTAD, 但其二聚体稳定性显著增强. 充分扩 展芳胺部分的共轭结构, 使 spiro-F3 的 HOMO 能级与钙 钛矿更为匹配，促进了电荷分离，空穴迁移率提升电荷 输运能力(表 1). 因而, 作者认为合理扩展共轭结构有望 大幅提升 spiro-OMeTAD 型空穴传输材料性能.

表 1 以螺二苆为中心核的空穴传输材料在钲钦矿太阳能电池中的应用

Table 1 Application of hole transport materials with spirofluorene core in perovskite solar cells

\begin{tabular}{|c|c|c|c|c|c|c|c|c|c|}
\hline HTMs & $\mathrm{HOMO} / \mathrm{eV}$ & LUMO/eV & $\sigma /\left(\mathrm{S} \cdot \mathrm{cm}^{-1}\right)$ & $\mu_{\mathrm{h}} /\left(\mathrm{cm}^{2} \cdot \mathrm{V}^{-1} \cdot \mathrm{s}^{-1}\right)$ & $V_{\mathrm{oc}} / \mathrm{V}$ & $J_{\mathrm{sc}} /\left(\mathrm{mA} \cdot \mathrm{cm}^{-2}\right)$ & $F F$ & $\mathrm{PCE} / \%$ & Ref. \\
\hline$p m$-spiro-OMeTAD & -5.31 & -2.31 & - & - & 1.01 & 21.1 & 65.2 & 13.9 & {$[42]$} \\
\hline$p o$-spiro-OMeTAD & -5.22 & -2.18 & - & 一 & 1.02 & 21.2 & 77.6 & 16.70 & {$[42]$} \\
\hline$p p$-spiro-OMeTAD & -5.22 & -2.28 & - & 一 & 1.00 & 20.7 & 71.1 & 14.90 & {$[42]$} \\
\hline 2,4-spiro-OMeTAD & -5.24 & -2.08 & 一 & 一 & 0.956 & 25.6 & 70.1 & 17.20 & {$[43]$} \\
\hline 3,4-spiro-OMeTAD & -5.26 & -2.16 & - & - & 0.752 & 20.1 & 59.9 & 9.10 & [43] \\
\hline $\mathrm{DM}$ & -5.27 & -2.36 & - & - & 1.11 & 24.8 & 81 & 22.30 & {$[44]$} \\
\hline $\mathrm{SC}$ & -5.26 & -2.35 & - & $3.15 \times 10^{-3}$ & 1.15 & 23.47 & 80.6 & 21.76 & {$[45]$} \\
\hline spiro-MeTAD1 & -4.49 & -0.83 & - & $5.0 \times 10^{-3}$ & 1.109 & 22.57 & 68.7 & 17.20 & {$[47]$} \\
\hline spiro-MeTAD2 & -4.55 & -0.84 & - & $5.0 \times 10^{-3}$ & 1.119 & 22.42 & 68 & 17.05 & {$[47]$} \\
\hline CF-SP-BTh & -5.38 & -3.73 & - & $3.14 \times 10^{-5}$ & 1.07 & 18.82 & 71 & 14.28 & [49] \\
\hline spiro- $m \mathrm{~F}$ & -5.19 & -2.23 & $2.60 \times 10^{-4}$ & $7.47 \times 10^{-3}$ & 1.16 & 26.35 & 81.5 & 24.82 & {$[50]$} \\
\hline spiro-oF & -5.06 & -2.04 & $2.25 \times 10^{-4}$ & $7.29 \times 10^{-3}$ & 1.16 & 26.34 & 80.9 & 24.50 & {$[50]$} \\
\hline spiro-OMeIm & -5.13 & -1.93 & - & $2.2 \times 10^{-4}$ & 1.1 & 20.35 & 75 & 16.78 & {$[51]$} \\
\hline spiro-TTB & -5.30 & -2.23 & - & $1.97 \times 10^{-3}$ & 1.07 & 22.02 & 78 & 18.38 & [48] \\
\hline G1 & -5.14 & -2.22 & $9.35 \times 10^{-5}$ & $1.03 \times 10^{-4}$ & 1.08 & 22.01 & 65 & 15.5 & {$[52]$} \\
\hline spiro-F1 & -5.31 & -2.39 & - & $1.75 \times 10^{-2}$ & - & - & - & - & [54] \\
\hline spiro-F2 & -5.42 & -2.55 & - & $2.60 \times 10^{-4}$ & - & - & - & - & {$[54]$} \\
\hline spiro-F3 & -5.10 & -2.38 & - & $7.59 \times 10^{-3}$ & - & 一 & - & - & {$[54]$} \\
\hline
\end{tabular}


spiro-OMeTAD 及其衍生材料的研究结果, 切实证 明基于螺芳基核构建高性能空穴传输材料的可行性和 前景. 但 SBF 制备成本高、修饰位置单一的问题, 限制 了 SBF 基材料的化学结构和性质优化, 有待通过螺结构 设计、合成方法创新、功能单元优化等方式, 发展新的 螺芳基空穴传输材料体系.

\section{4 螺[芴-9,9'-氧杂葸]基空穴传输材料}

螺 [芴 -9, 9' - 氧杂葱] (spiro[fluorene-9, 9'-xanthene], $\mathrm{SFX}$ )的结构及合成与 SBF 于 1930 年一同被报道 ${ }^{[39]}$, 当 时采用的制备路线与 SBF 相似, 即利用 2-位卤代苯基醚 的 Grignard 试剂与芴酮加成得到叔醇中间产物, 然后经 Friedel-Crafts 烷基化关环成螺芴类结构. 由于该制备方 法与 SBF 比较无明显优势, 因此 SFX 类材料的研究未 获得足够重视. 单纯从结构比较分析, SFX 与 SBF 的主 要差异在于螺原子两侧二元化的共轭体系; 此外, 由于 氧原子为 $\mathrm{sp}^{3}$ 杂化, 氧杂蒽单元并非绝对平面构型. 而 从反应性来看, SFX 氧杂葱侧可供修饰位置比 SBF 更活 泼和丰富, 有利于相关材料的结构衍生化 ${ }^{[12,55]}$. 随着新 的、高效合成方法的发现, 以及结构和反应性方面的优 势, SFX 单元在近 10 年得到学界和产业界的广泛关注; 尤其在空穴传输材料研究领域, 众多高性能 SFX 基分 子不断涌现, 结构、性能和成本方面的优势不断被发掘 出来.

\section{1 螺[芴-9, $9^{\prime}$-氧杂葸]的合成}

2006 年, 黄维、解令海等 ${ }^{[56]}$ 发现的高效 “一锅法” 制备方案, 为 SFX 类单元在有机光电领域的崛起奠定 了化学基础. 该路线是在甲烷磺酸催化下, 串联酚/芳胺 对芴酮羰基亲核加成及后续热力学控制的 Friedel-Crafts 环合反应, 高收率、宽底物范围合成 SFX 类螺结构(图 7). 二元共轭体系、灵活可控的卤代位置, 使 SFX 可经 $\mathrm{C}-\mathrm{C} 、 \mathrm{C}-\mathrm{N}$ 偶联反应进一步功能化, 为螺芳基半导体 材料分子设计搭建了新平台, 为深入探究其结构、性质、 性能间关系提供了多样化的模型 ${ }^{[57]}$.

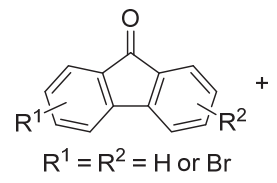

$\mathrm{R}^{1}=\mathrm{H} ; \mathrm{R}^{2}=\mathrm{Br}$

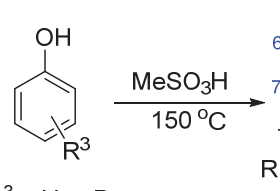

$\mathrm{R}^{3}=\mathrm{H}$ or $\mathrm{Br}$

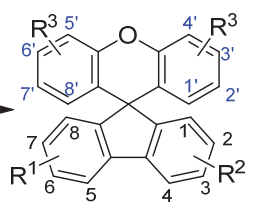
$R^{2}$

图 7 螺[芴-9,9'-氧杂葱]的合成路线

Figure 7 The synthesis route of spiro[fluorene-9,9'-xanthene]

\section{2 基于 SFX 核的空穴传输材料}

基于 SFX 的结构和性质特点, 由该类核衍生的空 穴传输材料在近期得以快速发展, 部分高性能材料的分 子结构见图 8 , 相应器件性能总结于表 2 中. 占肖卫 等 ${ }^{55}$ 较为系统地探索了 SFX 上引入芳胺单元空穴传输
材料的光电性质及太阳能电池性能. 其中, 分子 $m m$-SFX-2PA 和 $m p-S F X-2 P A$ 展现了良好的空穴输运应 用潜力. 二者的热分解温度相对 spiro-OMeTAD 提高了 $40 \sim 50{ }^{\circ} \mathrm{C}$, 而 HOMO 能级相对降低了 $0.5 \sim 0.9 \mathrm{eV}$. $m p-\mathrm{SFX}-2 \mathrm{PA}$ 基 $\mathrm{MAPbI}_{3}$ 太阳能电池器件效率达到 $16.8 \%$, 高于 spiro-OMeTAD 对照器件的 $15.5 \%$. 更为突 出的性能指标是: 空气环境中储存 $2000 \mathrm{~h}$ 后, 器件保持 了初始效率的 $90 \%$, 而 spiro-OMeTAD 对照器件只有最 初的 $28 \%$. 作者将优异的稳定性初步归因于 $m p-\mathrm{SFX}-2 \mathrm{PA}$ 薄膜疏水性的提升 (与水接触角 $111.4^{\circ}$, spiro-OMeTAD 薄膜 $80.6^{\circ}$ ). 该报道进一步考察了扩展 共轭对材料能级、空穴迁移率的影响，研究发现：无论 掺杂或非掺杂薄膜, 增加桥连苯环的分子 $m m-S F X-3 P A$ 和 $m p$-SFX-3PA, 其空穴迁移率相对增加前降低了一个 数量级, 这为 SFX 基空穴传输材料的合理功能化提供 了参考.

同时，国内外多个课题组报道了与 $m m-\mathrm{SFX}-2 \mathrm{PA}$ 和 $m p-\mathrm{SFX}-2 \mathrm{PA}$ 结构相同的材料, 如: X60. 其中, Sargent 与 Berlinguette 小组 ${ }^{[12]}$ 的合作研究系统分析了芳胺基团 取代位置影响材料能级和稳定性的规律. 对比 SFX 芴 端和氧杂葱端取代物的 HOMO 能级、空穴迁移率、热 分析数据发现: 芴端取代降低材料 HOMO 能级, 可提 升相应空穴传输层对空穴的抽提能力; 而氧杂葱端 $3^{\prime}, 6^{\prime}$-位取代提高了材料的热稳定性. 因此, HTM-FX'(与 $m p-\mathrm{SFX}-2 \mathrm{PA}$ 同构) 为空穴传输层的钲钛矿 $\left(\mathrm{Cs}_{0.05} \mathrm{FA}_{0.81} \mathrm{MA}_{0.14} \mathrm{PbI}_{2.55} \mathrm{Br}_{0.45}\right)$ 太阳能电池器件效率达到 $20.8 \%$, 高于 spiro-OMeTAD 对照器件的 $20.4 \%$, 与 $m m-\mathrm{SFX}-2 \mathrm{PA}$ 和 $m p$-SFX-2PA 效率趋势一致; 从而根据 精细的构效关系, 阐明了利用 SFX 单元设计高性能空 穴传输材料的基本原则.

根据该中心核的多功能性，为优化 SFX 的传输性 能，使用不同的取代基调控 HOMO 能级，可以方便地、 低成本地制备螺环传输材料 ${ }^{[58]}$. 基于 SFX 核结构, 通过 空穴传输功能基团的电子结构和位阻结构调控, 孙立成 研究组的 $\mathrm{Xu}$ 和 $\mathrm{Bi}$ 等 ${ }^{[58]}$ 开展了系统性的研究工作. 首先, 在 SFX 芴端 2,7-位连接二对甲氧基苯胺基，制备了与 HTM-F 同构的分子 X59. 器件空穴传输层掺杂 LiTFSI 和 $t \mathrm{BP}$ (4-叔丁基吡啶)后, 再辅助添加 FK209, PCE 达到 了 $19.8 \%$, 略低于 spiro-OMeTAD 对照器件的 20.8\%(如 图 9). 但根据 “效率-成本比率” 分析, 使用 X59 对整体 降低电池成本的优势明显, 为钙钛矿太阳能电池板的商 业化制造开辟了新途径. $\mathrm{Xu}$ 等[59]较早制备了与 $m m-\mathrm{SFX}-2 \mathrm{PA}$ 同构的空穴传输材料 X60, 即利用 $2,2^{\prime}, 7,7^{\prime}$-SFX 核替换 spiro-OMeTAD 中的 SBF. “一锅法” 螺环化和 $\mathrm{Pd}$ 催化 $\mathrm{C}-\mathrm{N}$ 偶联的普适性与高收率优势, 大 幅降低了材料制备成本, 钙钛矿电池的 PCE 高达 19.84\%，充分证明了 SFX 单元用于工业规模制造空穴 传输材料的潜力. 进一步地, $\mathrm{Xu}$ 等[60]不仅使用 SFX 作为 

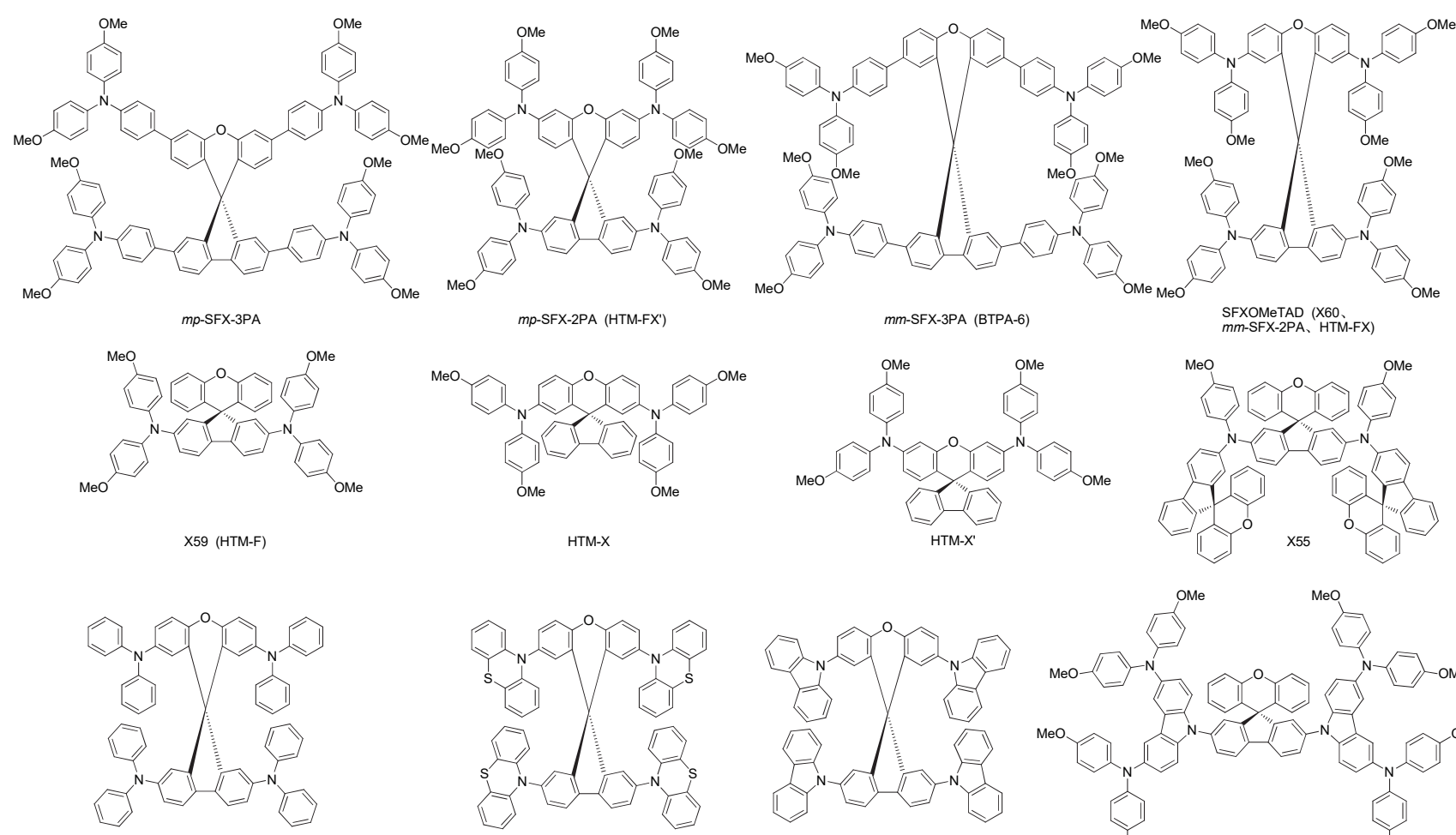

SFX-TAD (spiro-H)

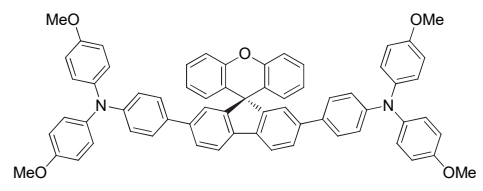

BTPA-4 (X59-P、Y1)

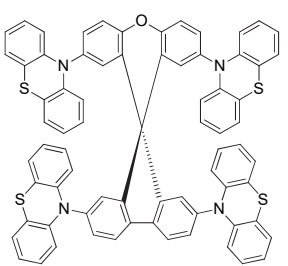

SFX-TPTZ

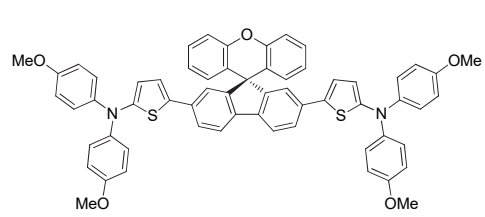

X59-T

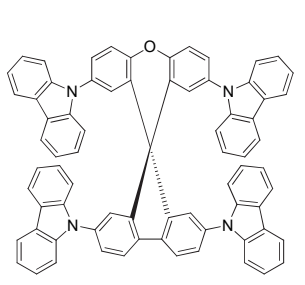

SFX-TCZ
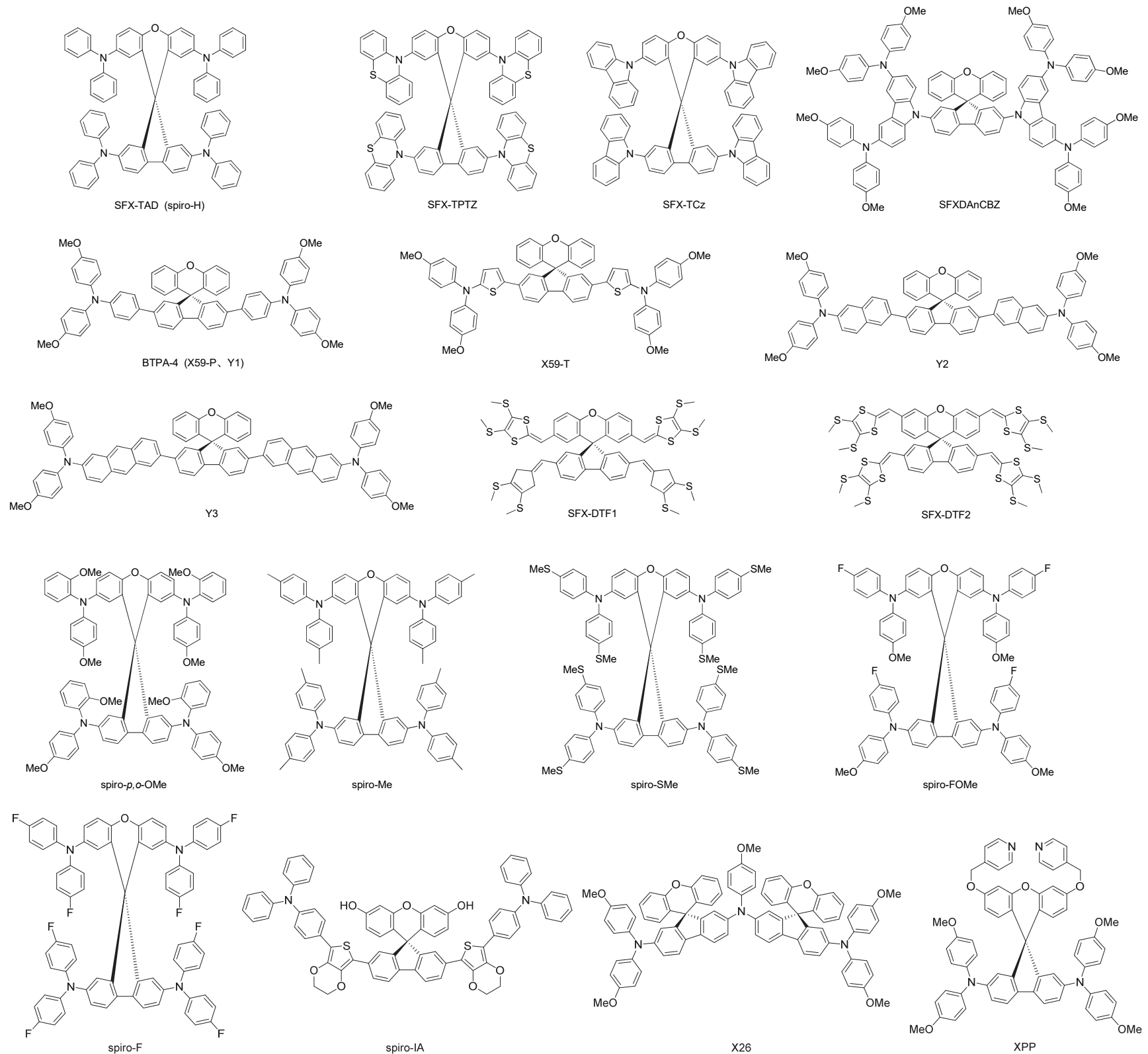

spiro-IA

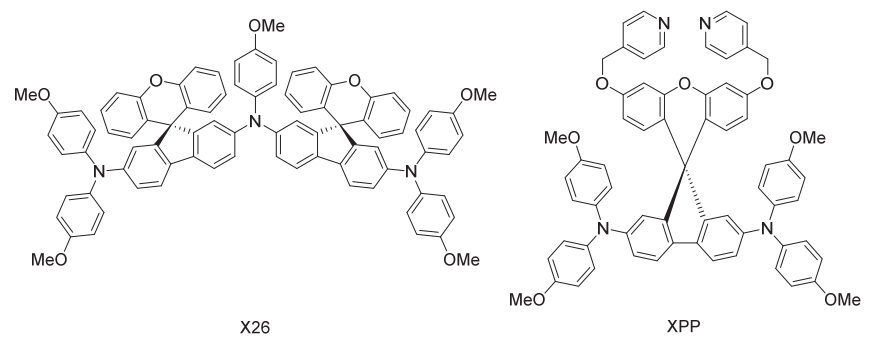




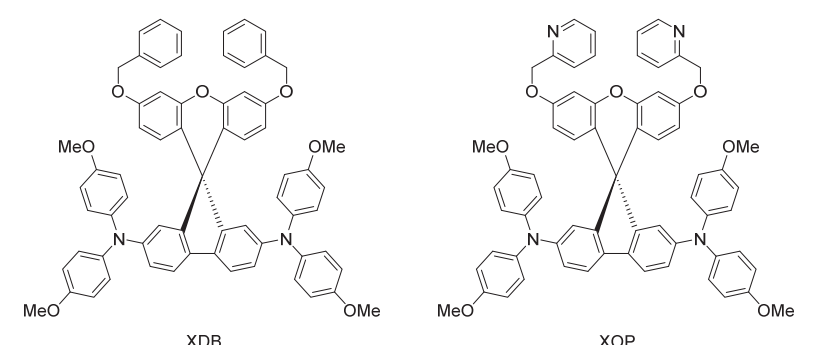

XDB

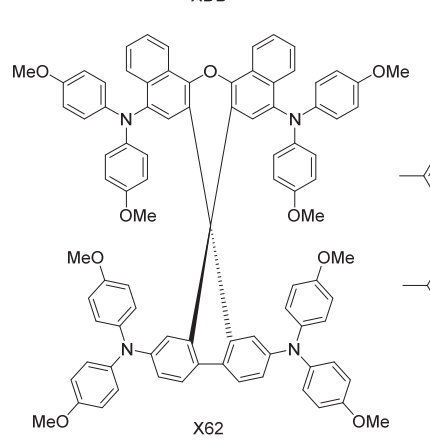

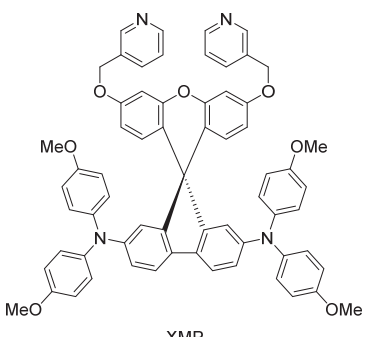

XMP

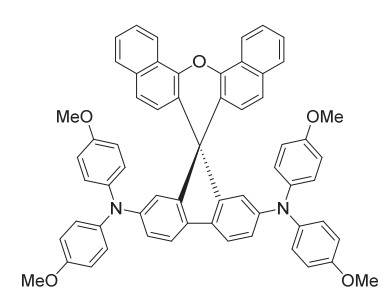

X61

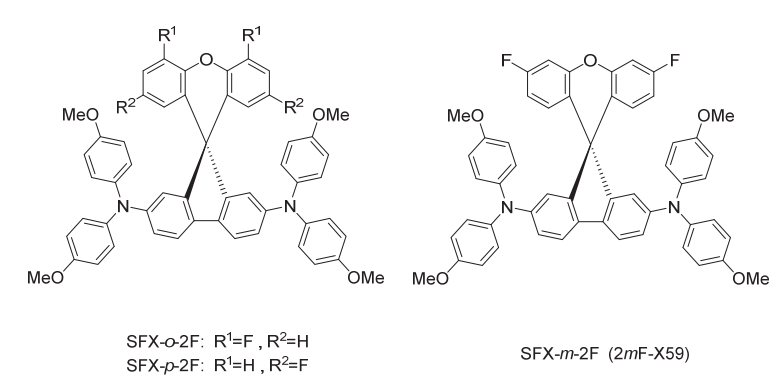

图 8 螺芴氧杂葱为中心核的空穴传输材料

Figure 8 Hole transport materials with spiro[fluorene-9,9'-xanthene] core in perovskite solar cells

表 2 以螺芴氧杂葱为中心核的空穴传输材料在钙钛矿太阳能电池中的应用

Table 2 Application of hole transport materials with spiro[fluorene-9,9'-xanthene] core in perovskite solar cells

\begin{tabular}{|c|c|c|c|c|c|c|c|c|c|}
\hline HTMs & $\mathrm{HOMO} / \mathrm{eV}$ & $\mathrm{LUMO} / \mathrm{eV}$ & $\sigma /\left(\mathrm{S} \cdot \mathrm{cm}^{-1}\right)$ & $\mu_{\mathrm{h}} /\left(\mathrm{cm}^{2} \cdot \mathrm{V}^{-1} \cdot \mathrm{s}^{-1}\right)$ & $V_{\mathrm{oc}} / \mathrm{V}$ & $J_{\mathrm{sc}} /\left(\mathrm{mA}^{\prime} \mathrm{cm}^{-2}\right)$ & $F F$ & $\mathrm{PCE} / \%$ & Ref. \\
\hline$m p$-SFX-3PA & -5.08 & -2.25 & - & $3.3 \times 10^{-5}$ & 1.00 & 18.94 & 18.9 & 14.05 & {$[55]$} \\
\hline$m p-\mathrm{SFX}-2 \mathrm{PA}$ & -4.92 & -1.98 & - & $1.5 \times 10^{-4}$ & 1.02 & 21.17 & 21.2 & 16.77 & [55] \\
\hline$m m$-SFX-3PA & -5.08 & -2.27 & - & $2.2 \times 10^{-5}$ & 1.01 & 18.02 & 18.0 & 13.25 & [55] \\
\hline$m m$-SFX-2PA & -4.89 & -1.97 & - & $9.9 \times 10^{-5}$ & 0.97 & 19.07 & 19.1 & 14.10 & [55] \\
\hline HTM-FX & -5.17 & -1.06 & - & $1.4 \times 10^{-4}$ & 1.16 & 21.2 & 74 & 18.2 & {$[12]$} \\
\hline HTM-F & -5.17 & -1.12 & - & $4 \times 10^{-5}$ & 1.08 & 14.7 & 41 & 6.5 & {$[12]$} \\
\hline HTM-X & -5.26 & -1.20 & - & $5 \times 10^{-5}$ & 0.88 & 3.8 & 32 & 1.1 & [12] \\
\hline HTM-X' & -5.47 & -1.14 & - & $3 \times 10^{-5}$ & 0.77 & 1.4 & 26 & 0.2 & {$[12]$} \\
\hline HTM-FX' & -5.16 & -1.03 & - & $4.8 \times 10^{-4}$ & 1.17 & 21.7 & 78 & 19.7 & [12] \\
\hline X59 & -5.15 & -2.10 & $1.9 \times 10^{-4}$ & $5.5 \times 10^{-5}$ & 1.13 & 23.4 & 23.4 & 19.8 & [58] \\
\hline BТРA-4 & -5.35 & -2.45 & $2.18 \times 10^{-4}$ & - & 0.946 & 18.91 & 51.5 & 9.21 & [64] \\
\hline ВТРA-5 & -5.37 & -2.48 & $2.69 \times 10^{-4}$ & - & 0.959 & 18.70 & 63.0 & 11.30 & [64] \\
\hline ВТРА-6 & -5.34 & -2.43 & $2.47 \times 10^{-4}$ & - & 0.978 & 20.57 & 57.5 & 11.57 & [64] \\
\hline SFX-OMeTAD & -5.16 & -2.20 & $1.4 \times 10^{-5}$ & - & 0.96 & 21.2 & 21.2 & 11.1 & {$[60,61]$} \\
\hline $\mathrm{SFXDAnCBZ}^{a}$ & -4.95 & -2.16 & - & $4.28 \times 10^{-4}$ & 1.09 & 23.10 & 83 & 20.87 & [63] \\
\hline $\mathrm{Y} 1^{a}$ & -5.35 & -2.46 & - & $1.53 \times 10^{-4}$ & 1.05 & 21.35 & 73.9 & 16.29 & [66] \\
\hline $\mathrm{Y}^{a}{ }^{a}$ & -5.39 & -2.59 & - & $3.97 \times 10^{-5}$ & 1.03 & 20.14 & 66.1 & 13.73 & [66] \\
\hline $\mathrm{Y}^{a}{ }^{a}$ & -5.35 & -2.91 & - & $8.78 \times 10^{-5}$ & 0.95 & 10.86 & 76.1 & 15.15 & [66] \\
\hline $\mathrm{X} 55$ & -5.23 & -2.26 & $8.43 \times 10^{-4}$ & $6.81 \times 10^{-4}$ & 1.15 & 23.4 & 77 & 20.8 & {$[60]$} \\
\hline SFX-DTF1 & -5.16 & -2.53 & - & $1.51 \times 10^{-4}$ & 1.03 & 19.23 & 53.8 & 10.67 & [68] \\
\hline SFX-DTF2 & -5.19 & -2.57 & - & $3.05 \times 10^{-5}$ & 0.98 & 19.05 & 47.1 & 8.78 & [68] \\
\hline X26 & -5.08 & -2.22 & $2.79 \times 10^{-4}$ & $4.31 \times 10^{-4}$ & 1.11 & 24.3 & 75 & 20.2 & [69] \\
\hline X36 & 5.12 & -2.14 & $5.05 \times 10^{-4}$ & $1.97 \times 10^{-4}$ & 1.06 & 23.7 & 76 & 18.9 & [69] \\
\hline SFX-TPAM $^{a}$ & -5.21 & -2.29 & - & - & 1.01 & 19.12 & 53 & 10.23 & [70] \\
\hline SFX-TPA $^{a}$ & -5.57 & -2.63 & - & - & 0.64 & 15.35 & 39 & 3.83 & [70] \\
\hline X60 & -4.49 & -2.30 & $1.1 \times 10^{-4}$ & $1.9 \times 10^{-4}$ & 1.12 & 23.4 & 79 & 20.9 & [69] \\
\hline spiro- $p, o-\mathrm{OMe}$ & -4.82 & -2.38 & $3.7 \times 10^{-5}$ & - & 1.03 & 13.5 & 75 & 3.5 & [25] \\
\hline spiro-Me & -4.88 & -2.25 & $2.5 \times 10^{-4}$ & - & 0.68 & 0.16 & 34 & 0.04 & [25] \\
\hline spiro-SMe & -5.09 & -2.13 & $6.9 \times 10^{-5}$ & - & 0.92 & 1.25 & 34 & 0.39 & {$[25]$} \\
\hline spiro-FOMe & -4.96 & -2.17 & $1.9 \times 10^{-6}$ & - & 0.77 & 0.04 & 20 & 0.01 & [25] \\
\hline spiro-H & -5.03 & -2.18 & $2.8 \times 10^{-5}$ & - & 0.75 & 0.3 & 14 & 0.04 & [25] \\
\hline spiro-IA $^{a}$ & -5.24 & -2.70 & $2.10 \times 10^{-4}$ & - & 1.04 & 22.14 & 67.9 & 15.66 & [71] \\
\hline XDB & -5.15 & -2.11 & - & $7.3 \times 10^{-5}$ & 1.02 & 19.9 & 76.1 & 15.5 & [73] \\
\hline XOP & -5.15 & -2.11 & - & $9.7 \times 10^{-5}$ & 1.06 & 19.6 & 76.5 & 15.9 & [73] \\
\hline XMP & -5.15 & -2.11 & - & $1.3 \times 10^{-4}$ & 1.07 & 20.5 & 77.2 & 16.9 & [73] \\
\hline XPP & -5.15 & -2.11 & - & $1.6 \times 10^{-4}$ & 1.06 & 21.3 & 78.4 & 17.7 & [73] \\
\hline $\mathrm{X} 61^{a}$ & -5.11 & -2.09 & $3.98 \times 10^{-6}$ & $3.91 \times 10^{-5}$ & 0.97 & 18.6 & 44.1 & 8.0 & [74] \\
\hline $\mathrm{X} 62^{a}$ & -5.14 & -2.22 & $5.14 \times 10^{-6}$ & $7.95 \times 10^{-5}$ & 1.01 & 22.4 & 70.4 & 15.9 & [74] \\
\hline
\end{tabular}




\begin{tabular}{|c|c|c|c|c|c|c|c|c|c|}
\hline HTMs & $\mathrm{HOMO} / \mathrm{eV}$ & $\mathrm{LUMO} / \mathrm{eV}$ & $\sigma /\left(\mathrm{S} \cdot \mathrm{cm}^{-1}\right)$ & $\mu_{\mathrm{h}} /\left(\mathrm{cm}^{2} \cdot \mathrm{V}^{-1} \cdot \mathrm{s}^{-1}\right)$ & $V_{\mathrm{oc}} / \mathrm{V}$ & $J_{\mathrm{sc}} /\left(\mathrm{mA} \cdot \mathrm{cm}^{-2}\right)$ & $F F$ & $\mathrm{PCE} / \%$ & Ref. \\
\hline $2 m \mathrm{~F}-\mathrm{X} 59$ & -5.14 & -2.40 & - & $7.14 \times 10^{-5}$ & 1.01 & 24.97 & 71.6 & 18.13 & {$[76,77]$} \\
\hline SFX-o-2F & -5.16 & -2.24 & - & $7.4 \times 10^{-6}$ & 1.12 & 17.59 & 48.8 & 9.7 & {$[78]$} \\
\hline SFX-m-2F & -5.18 & -2.30 & - & $6.07 \times 10^{-5}$ & 1.16 & 22.64 & 71.9 & 18.86 & [78] \\
\hline SFX- $p-2 \mathrm{~F}$ & -5.18 & -2.28 & - & $1.79 \times 10^{-5}$ & 1.14 & 22.23 & 61.5 & 16.33 & [78] \\
\hline
\end{tabular}

${ }^{a}$ Undoped HTM.

核结构替代了 SBF, 并利用 SFX 的芴端改造了芳胺单元 结构, 即扩展共轭的同时增加了氧杂葱位阻, 获得空穴 传输材料 X55, 该设计协同强化了 SFX 的位阻和电子结 构特点. X55 的空穴迁移率 $\left(6.81 \times 10^{-4} \mathrm{~cm}^{2} \cdot \mathrm{V}^{-1} \cdot \mathrm{s}^{-1}\right)$ 较 spiro-OMeTAD 提高近 5 倍. 以 $\left[\mathrm{HC}\left(\mathrm{NH}_{2}\right)_{2}\right]_{0.85}$ $\left[\mathrm{CH}_{3} \mathrm{NH}_{3}\right]_{0.15} \mathrm{~Pb}\left[\mathrm{I}_{0.85} \mathrm{Br}_{0.15}\right]_{3}$ 为器件的平均 $\mathrm{PCE}$ 为 $19.4 \%$ $\pm 0.09 \%$ (最高 20.8\%), 明显优于 spiro-OMeTAD 基对照 器件 $17.4 \% \pm 1.0 \%$ 的效率(最高 $18.8 \%$ ). 未封装器件在 $20 \%$ 湿度空气环境放置 6 个月后, X55 基器件效率下降 仅有 7\%, 而 spiro-OMeTAD 基电池效率降低了 $10 \%$. 薄 膜的瞬态吸收光谱和形貌分析揭示了 X55 具有优异空 穴输运和出色稳定性的原因: 更快的荧光衰减及均一、 致密的微纳尺度形貌, 使 X55 的性能得以超越 spiro-OMeTAD. 以上优化 SFX 类材料的探索, 特别是 含三个 SFX 单元分子 X55 取得的突破性进展, 充分揭示 了使用 SFX 构建高性能空穴传输材料的潜力.
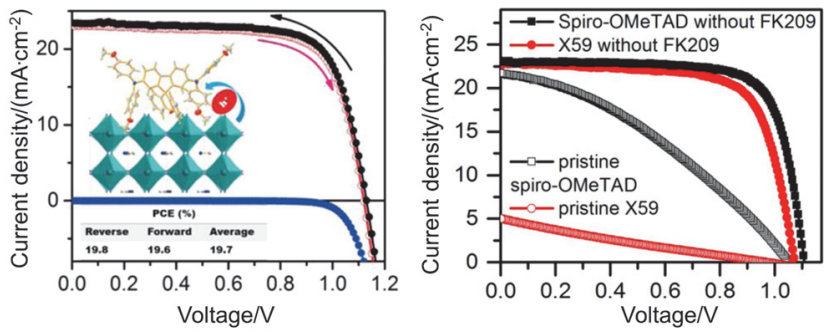

图 9 使用 X59 的钻钛矿太阳能电池的稳定性. (a)使用 X59 对最佳电 池进行反向和正向扫描, 测量的 $J-V$ 曲线; (b)基于 X59 和 spiroOMeTAD 的 PSC 的 $J-V$ 曲线(含或不含 FK209), 原始 HTMs 表示没有 LiTFSI、 $t$ BP 或 FK209 $9^{[58]}$

Figure 9 Stability of perovskite cells using X59. (a) $J-V$ curves measured by reverse and forward scans of the best cell using X59; (b) $J-V$ curves of PSCs based on X59 and spiro-OMeTAD with and without FK209, pristine HTM means no LiTFSI, $t$ BP or FK209 $9^{[58]}$

Maciejczyk 等[1]]分别利用二苯胺、咔唑、吩噻嗪、 二对甲氧基苯胺修饰 SFX 的 2,2',7,7'-位, 获得四种空穴 传输材料：SFX-TAD、SFX-TCZ、SFX-TPTZ 和 SFX-OMeTAD. 从 HOMO 能级调控效果来看, 按 SFX-OMeTAD、SFX-TAD、SFX-TPTZ、SFX-TCZ 的顺 序, HOMO 能级依次降低. 钻钣矿电池性能测试显示, SFX-MeOTAD 与 spiro-OMeTAD 基器件的效率相当. 此 外, $\mathrm{Xu}^{[59]}$ 和 Maciejczyk ${ }^{[6]}$ 等依据商品化原料价格和步骤 经济性，对比了 SFX 与 SBF 的澳代中间体及对应空穴 传输材料的制备成本. 高效的“一锅法”方式赋予了 SFX 显著的成本优势, 估算结果显示 SFX 四溴代物成本仅 为 SBF 的 $1 / 30$ 左右; 而空穴传输材料 SFX-MeOTAD 合
成成本只有相应 SBF 基类似物 spiro-MeOTAD 的 $1 / 5$.

Seok 组 ${ }^{[62]}$ 采用二对甲氧基苯胺支化的咔唑为空穴 输运单元, 连接 SFX 的 2,7-位, 合成了分子 SFXDAnCBZ. 以非掺杂的 SFXDAnCBZ 为空穴传输层, 在 $100 \mathrm{~mW} \cdot \mathrm{cm}^{-2} \mathrm{AM} 1.5 \mathrm{G}$ 模拟太阳光照射下，电池效率 达到了 $20.87 \%$ (图 10). 由于非掺杂空穴传输层能更好地 避免相分离问题，且效率和稳定性测试结果均与 spiro-OMeTAD 对照器件相当 ${ }^{[63]}$, 凸显出该分子的实用 化潜力.
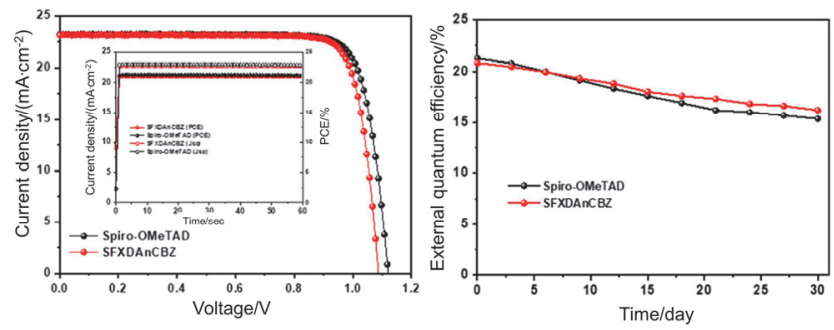

图 10 使用 SFXDAnCBZ 的钻钛矿太阳能电池的稳定性. (a) SFXDAnCBZ 和 spiro-OMeTAD 的反向扫描 $J-V$ 曲线, SFXDAnCBZ 和 spiro-OMeTAD 的最大功率点跟踪(插图); (b) spiro-OMeTAD 和 SFXDAnCBZ 的 PCE 曲线(在 $30 \%$ 湿度和 $30{ }^{\circ} \mathrm{C}$ 下未封装) ${ }^{[62]}$

Figure 10 Stability of perovskite cells using SFXDAnCBZ. a, J-V curves of SFXDAnCBZ and spiro-OMeTAD measured in reversed scan direction, maximum power point tracking of SFXDAnCBZ and spiro-OMeTAD (inset); (b) PCE curves of spiro-OMeTAD and SFXDAnCBZ (not encapsulated at $30 \%$ humidity and $30{ }^{\circ} \mathrm{C}$ )

$\mathrm{Wu}$ 等 ${ }^{[64]}$ 在 X59 的基础上, 通过桥连苯环扩展芳胺 共轭体系及增加对氧杂葱部分功能化，合成了分子 BTPA-4 和 BTPA-6. BTPA-4 的 HOMO 能级 $(-5.35 \mathrm{eV})$ 相对 X59 下降 $0.2 \mathrm{eV}$, 有利于提升电池的 $V_{\mathrm{oc}}$. 氧杂葱 $2^{\prime}, 7^{\prime}$-位增加取代后, BTPA-6 的 HOMO 能级与 BTPA-4 保持相同. 由于电活性基团数目与材料性能正相关, 使 用 BTPA-6 为空穴传输材料的电池效率 $\left(0.375 \mathrm{~cm}^{2}\right.$, 14.4\%) 显著高于 BTPA-4 基器件, 基本接近采用 spiro-OMeTAD 的对照器件 $15 \%$ 的 PCE, 且器件长期稳 定性更高, 合成成本较 spiro-OMeTAD 降低三分之二. Zhang 等 ${ }^{[65]}$ 通过理论计算考察了苯和噻吩 $\pi$ 桥对材料能 级、空穴迁移率的影响. 结果表明 X59-P(与 BTPA-4 同 构)和 X59-T 的空穴迁移率处于同一数量级, 但噻吩单 元的强给电子作用使分子 HOMO 能级相对抬升, 而弱 的位阻扭转效应则降低了材料的带隙. 二者的稳定性评 估均优于 spiro-OMeTAD.

同样以 X59 为结构基础，再经过分子结构模拟优 化, Zhang 等 ${ }^{[6]]}$ 在 SFX 和芳胺之间插入苯、薺、葱桥连 
单元, 得到了 Y-1、Y-2 和 Y-3. 桥连单元增强了分子的 平面型并延长了分子的共轭体系, 材料的带隙窄化且 HOMO 能级下降到 5.35 5.39 eV. 同时, 分子内形成了 电荷转移态(intramolecular charge transfer state, ICT), 从 而在空穴传输层产生自掺杂效应, 提升了材料的空穴迁 移率. 使用 Y-1 为非掺杂空穴传输层电池的 PCE 达到 $16.29 \%$, 高于非掺杂 X59 基对照器件的 $14.64 \%$. 该结果 说明适当引入桥连片段诱导分子内电荷转移态, 是发展 高性能非掺杂空穴传输材料的有效手段.

SFX 的衍生物也可通过扩展共轭结构或是调节取 代基位次的方式调控能级, 使 HTMs 具有良好的溶解 性、较高的空穴迁移率、有效的空穴提取和电子阻断能 力. Liu 等 ${ }^{[55]}$ 设计并合成了 $m p-S F X-3 P A$ 和 $m m-$ SFX-3PA 、 $m p$-SFX-2PA 和 $m m$-SFX-2PA (X60、 spiro-OMeTAD). 结果表明, 共轭结构的扩展及其取代 位置会影响 HTMs 的空穴迁移率. 其中, $m p-S F X-2 \mathrm{PA}$ 具 有更高的空穴迁移率, HOMO 能级更匹配, 电荷提取和 传输能力更优, 表现出最好 PCE (16.8\%), 高于相同条 件下的 spiro-OMeTAD 器件效率. $m p$-SFX-2PA 在采用 $\mathrm{FAPbI}_{3} / \mathrm{MAPbBr}_{3}$ 钙钛矿混合层的器件时 $\mathrm{PCE}$ 达到 $17.7 \%$, 与同条件下的 spiro-OMeTAD 器件(PCE: 17.6\%) 相当. 此外, $m p-S F X-2 P A$ 的器件在环境中储存 $2000 \mathrm{~h}$ 后 保留 $90 \%$ 的初始 PCE, 显示出更好的稳定性, 掺杂的 $m p$-SFX-2PA 器件具有更好的空穴迁移率和更高的疏水 性，更具有应用在 PSCs 上的商业价值.

四硫富瓦烯衍生物 (tetrathiafulvalene derivative, $\mathrm{TTF}$ )具有较强的给电子能力以及独特的光物理和电化 学性质, 在有机光电材料领域得到极大关注 ${ }^{[67]}$. 而 TTF 的半片段二硫富瓦烯(dithiafulvene, DTF) 在性能上与 TTF 类似, 且结构更为简单, 便于修饰在多种碳骨架上. $\mathrm{Wu}$ 等 ${ }^{[68]}$ 以四醛基化 SFX 中间体为原料, 通过 Wittig 缩 合反应, 得到两种二硫富瓦烯功能化的空穴传输材料 SFX-DTF1 和 SFX-DTF2. 空穴迁移流测试表明 2,2',7,7'位修饰的 SFX-DTF1 电荷输运能力是 SFX-DTF2 和 spiro-OMeTAD 的 4.9 倍和 2.3 倍. SFX-DTF1 良好的电 荷输运性质和疏水特性使其非掺杂电池器件 PCE 达到 $10.67 \%$, 高于 SFX-DTF2 基器件的 $8.78 \%$ 及 spiro-OMeTAD 基器件的 3.37\%. 研究发现, SFX 结构对 材料电导率、能级以及薄膜形貌、稳定性有显著影响. 以 $\mathrm{X} 26^{[69]}$ 为空穴传输材料的 $\mathrm{FA}_{0.85} \mathrm{MA}_{0.15} \mathrm{~Pb}\left(\mathrm{I}_{0.85} \mathrm{Br}_{0.15}\right)_{3}$ 钙 钛矿层器件, PCE 可达到 $20.2 \%$, 且器件在黑暗环境下 老化 5 个月后 PCE 仍保持在 $18.8 \%$, 表现优良的稳定性. Govindan 等[70]制备了甲基 TPA 取代 SFX 的 2,2',7,7'-位 的空穴传输分子 SFX-TPAM, 其 HOMO 能级较 spiro-OMeTAD 降低了 $0.69 \mathrm{eV}$, 从而与与钙钛矿层能级 更加匹配, 电荷输运能力得到提高. 在非掺杂倒置结构 器件中, 电池 PCE 为 $10.23 \%$, 优于对照的 spiro-OMeTAD 基电池 $(8.17 \%)$. 在 X60 分子结构基础上, Chiykowski 等 ${ }^{[25]}$ 设计并合成了一系列以 2,2' $7,7^{\prime}$-位 SFX
为中心的 HTMs: spiro- $p, o-\mathrm{OMe}$ 、 spiro-Me、spiro-SMe、 spiro-FOMe 和 spiro-H, 这些 HTM 的取代基在空间体 积、吸电强度和位置上都有所不同. 结果表明, 空间体 积庞大的非极性取代基增加了 HTMs 的空穴迁移率. 在 随后的工作中又通过对比取代位置发现, 苯胺基团在 SFX 中芴端 2,7-位取代, 提升材料的空穴抽提能力, 而 对氧杂葱端 $3^{\prime}, 6^{\prime}$-位取代时, 材料的玻璃化转变温度和 空穴迁移率升高 ${ }^{[12]}$. 这种 2,3', $6^{\prime}, 7$-位取代的协同效应充 分体现了 SFX 二元化螺共轭的优势, 2,3', $6^{\prime}, 7$-位取代分 子 HTM-FX'表现出更低的还原电位和更高的玻璃态转 化温度、空穴迁移率，相应电池的 PCE 高达 20.8\%. 该 结果从结构和性能角度, 阐明了利用 SFX 设计高性能 空穴传输材料的合理方法. Abdellah 等[71]利用 SFX 的 “一锅法” 低成本合成优势，制备芴端共轭扩展、氧杂葱 端羟基取代的空穴传输材料 spiro-IA. 在极性非质子和 质子溶剂中, spiro-IA 均表现出良好的溶解性. 相对 spiro-OMeTAD, spiro-IA 的吸收光谱红移, Stokes 位移增 大. 采用 $\left(\mathrm{FAPbI}_{3}\right)_{0.85}\left(\mathrm{MAPbBr}_{3}\right)_{0.15}$ 为活性层的非掺杂 spiro-IA 基器件 PCE 达到了 $15.66 \%$, 与掺杂的 spiro-OMeTAD 基电池效率相当(PCE：15.93\%). 该结果 从技术和成本角度验证了 SFX 基空穴传输材料替代 spiro-OMeTAD 的可行性.

除 HOMO 能级和空穴迁移率等本征性质因素外, 钙钛矿吸光材料本身也会产生一定的缺陷, 这种缺陷是 由于 $t \mathrm{BP}$ 这一能显著提高 PCE 和稳态性的复合阻断剂 的引入从而引起的钙钛矿层 $\mathrm{PbI}_{2}$ 被络合而产生的缺陷. 空穴传输分子在界面处与钙钛矿吸光材料的分子间作 用可控制 $\mathrm{Pb}^{2+}$ 离子缺陷 ${ }^{[72]}$ 由于分子几何形状的空间位 阻效应, 吡啶氮原子很容易钝化钙钛矿薄膜表面的 $\mathrm{Pb}^{2+}$ 形成强化学键, Xu 等[73]制备了 XDB、XOP、XMP 和 XPP 四种在 SFX 的 $3^{\prime}, 6^{\prime}$-位引入吡啶基团的 HTMs，从而消除 了添加 $t \mathrm{BP}$ 带来的影响. XPP 在以 $\left[\mathrm{HC}\left(\mathrm{NH}_{2}\right)_{2}\right]_{0.85}\left(\mathrm{CH}_{3} \mathrm{NH}_{3}\right)_{0.15} \mathrm{~Pb}\left(\mathrm{I}_{0.85} \mathrm{Br}_{0.15}\right)_{3}$ 为钙钛矿层的 器件时 PCE 达 $17.2 \%$, 远高于非掺杂 spiro-OMeTAD 的 $\mathrm{PCE}(5.5 \%)$, 这首次实现了无 $t \mathrm{BP}$ 器件的高的 PCE 及良 好的稳定性. 其中 XPP 的两个吡啶氮原子都很容易与 $\mathrm{Pb}$ 形成强化学键, 且与钙钛矿的结合能最大 $(605.73$ $\left.\mathrm{kJ} \bullet \mathrm{mol}^{-1}\right)$ (如图 11). 结果表明, 吡啶功能化的 HTMs 具 有更好的空穴提取和传输能力, 为开发高效稳定的无 $t \mathrm{BP}$ 掺杂 HTMs 提供了新思路. 随后, $\mathrm{Xu}$ 等 ${ }^{[74]}$ 制备了 X61 和 X62 两种新型无掺杂的 HTMs，其中 X62 基电池 的 PCE 高达 $15.9 \%$, 高于 spiro-OMeTAD 基对照器件 $10.8 \%$ 的 PCE.

除了 PSCs 表面有离子缺陷会影响器件性能, PSCs 还容易受到环境中的水和氧等因素的影响而发生降解 从而影响器件的性能. 因此, 作为 PSCs 表面层的 HTMs 还应具有保护钙钛矿材料免受水分腐蚀的作用. 在提高 空穴迁移率和匹配能级的同时，也需要考虑 HTMs 疏水 性. 氟化是提高有机分子空穴传输材料疏水性、降低 


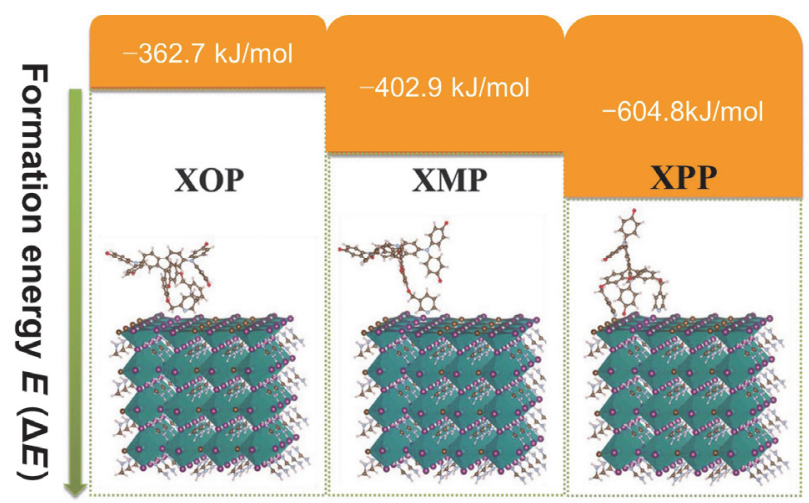

图 11 DFT 计算的 XOP、XMP、XPP 与钲钛矿晶体中暴露的 $\mathrm{Pb}$ 原 子之间的化学结合能 ${ }^{[73]}$

Figure 11 DFT calculation of the chemically bonded binding energy level between XOP, XMP, XPP and the exposed $\mathrm{Pb}$ atoms in perovskite crystal $^{[73]}$

HOMO 能级、促进电荷输运等性能的一种分子设计策 略 ${ }^{[75]}$. Guo 等 ${ }^{[76]}$ 设计并低成本合成了 $2 m \mathrm{~F}-\mathrm{X} 59$, 与 spiro-OMeTAD (HOMO: $-5.13 \mathrm{eV}$ )相比, $2 m \mathrm{~F}-\mathrm{X} 59$ 具有 略低的 HOMO 能级 $(-5.14 \mathrm{eV})$, 同时具有良好的空穴 迁移率和疏水性(如图 12).

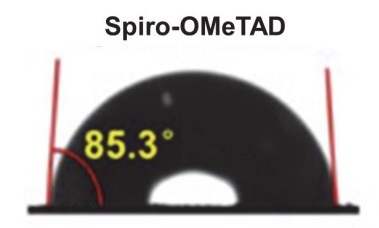

$2 m F-X 59$

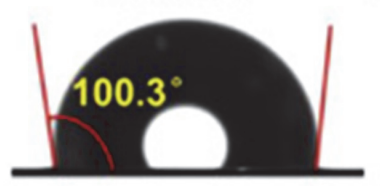

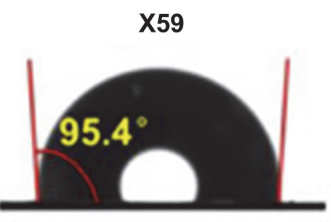

$2 m \mathrm{~F}-\mathrm{X} 59(4 \%(w) \mathrm{F} 4 \mathrm{TCNQ})$

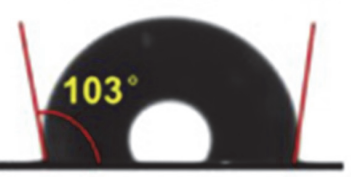

图 12 水在 X59, $2 m F-\mathrm{X} 59$, 添加 F4TCNQ $(w=4 \%)$ 优化的 $2 m F-\mathrm{X} 59$ 和 spiro-OMeTAD 薄膜表面的接触角 ${ }^{[76]}$

Figure 12 Water contact angles on X59, $2 m \mathrm{~F}-\mathrm{X} 59$, F4TCNQ $(w=4 \%)$-optimized-2mF-X59 and spiro-OMeTAD films ${ }^{[76]}$

在掺杂剂 F4TCNQ 的加入后, $2 m \mathrm{~F}-\mathrm{X} 59$ 进一步降低 HOMO 能级 $(-5.19 \mathrm{eV})$ 并改善其空穴迁移率, 优化后的 $2 m \mathrm{~F}-\mathrm{X} 59$ 器件在不使用 $\mathrm{Li}$ 掺杂剂 $\mathrm{CH}_{3} \mathrm{NH}_{3} \mathrm{PbI}_{3}$ 为钙钛矿 层的情况下, 其 $\mathrm{PCE}$ 可达到 $18.13 \%$, 以 $\mathrm{CsPbI}_{2} \mathrm{Br}$ 为 PSCs 时, 所获得的 PCE (13.42\%)也维持在较高的水 平 ${ }^{[77]}$. 更重要的是, 无敏感掺杂剂的 $2 m \mathrm{~F}-\mathrm{X} 59$ 器件暴露 在空气下 $500 \mathrm{~h}$ 以上仍能保持 $95 \%$ 的初始性能, 表现出 比掺杂敏感掺杂剂的 spiro-OMeTAD 的 PSCs 更好的长 期稳定性. 氟取代位置的不同对所得到 HTMs 性能有显 著的变化, $\mathrm{Li}$ 等 ${ }^{[78]}$ 制备了三种在 $\mathrm{SFX}$ 氧杂葱端氟化的 HTMs: SFX- $o-2 \mathrm{~F} 、 \mathrm{SFX}-p-2 \mathrm{~F}$ 及 $\mathrm{SFX}-m-2 \mathrm{~F}$, 以 $\mathrm{Cs}_{0.05}\left(\mathrm{MA}_{0.13} \mathrm{FA}_{0.87}\right)_{0.95} \mathrm{~Pb}\left(\mathrm{I}_{0.83} \mathrm{Br}_{0.17}\right)_{3}$ 为活性层的 $\mathrm{n}-\mathrm{i}-\mathrm{p}$ 型 器件效率分别达到 $9.9 \% 、 16.33 \%$ 和 $18.86 \%$. 为钻钛矿 层时表现出了较为优异的性能. 此外, 在环境条件下,
SFX- $m$-2F 比 spiro-OMeTAD 更稳定. 结果表明，氟化能 明显改善薄膜形貌和调控器件性能.

\section{5 含 N/S 原子的螺芳基 HTMs}

除了经典的 SBF 和 SFX 中心核, 作为同样具有刚 性的十字交叉结构的螺芳基化合物，10-苯基-10H-螺[呋 啶 -9,9'- 芴 ] (10-phenyl-10H-spiro[acridine-9,9'-fluorene], SAF) 和 螺 [ 芴 -9,9'- 硫杂葸 ] (Spiro[fluorene-9,9'thioanthrene], SFT) 的空穴传输材料近年来也在钙钛矿 太阳能电池中得到了应用. SAF 和 SFT 的合成方法与 SBF 相比类似, 所合成的 HTMs 因空穴迁移率较为可观 而逐渐被重视. 与 SBF 和 SFX 为中心核的 HTMs 相比, 其中以 SAF 为中心核的 HTMs 其 LUMO 能级高, 可以 有效地阻止电子的传输, 进一步降低了钙钛矿太阳能电 池中的激子复合率. SAF、SFT 基分子不断涌现，结构、 性能和成本方面的优势不断被发掘出来.

\section{1 含氮/硫螺环芳香骨架的合成}

如图 13-(1)式, SFT 的合成是在-78 ${ }^{\circ} \mathrm{C}$ 用锂-卤素交 换 反应处理 2,7-二溴-9H-硫杂葱-9-酮，然后通过 Friedel-Crafts 反应进行分子内闭环，以获得螺环结 构 ${ }^{[79]}$. 如图 13-(2)式, SAF 的合成与 SFT 方法类似 ${ }^{[80]}$. $\mathrm{SAF}$ 中的氮原子采用 $\mathrm{sp}^{3}$ 杂化, 比 SFX 多连接一个苯环, 可供修饰位置比 SFX 更活泼和丰富, SFT 可以看作是一 个硫原子被结合到 SBF 中, 得到了新的螺环结构. 总之, SAF 和 SFT 为新的分子设计与发展提供了巨大的空间.

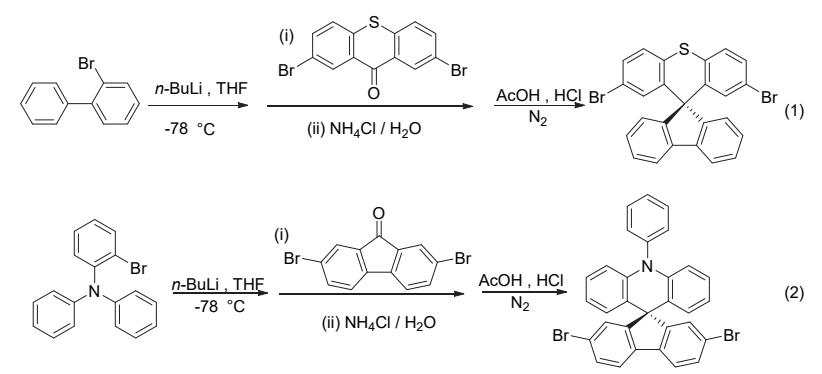

图 13 螺[芴-9,9'-硫杂葱]和 10-苯基-10H-螺环 [ 呋啶-9,9'-夰]衍生物的 合成路线 ${ }^{[79-80]}$

Figure 13 The synthesis routes of spiro[fluorene-9,9'-thioanthrene] derivatives and 10-phenyl-10H-spiro[acridine-9,9'-fluorene] derivatives $^{[79-80]}$

\section{2 基于含氮螺环芳香骨架的 HTMs}

在 SBF 和 SFX 螺环基础上, 研究者进一步发展了 一系列含 $\mathrm{N}$ 或 $\mathrm{S}$ 等杂原子的核结构, 并用于构建新的空 穴传输材料(图 14), 部分电池性能数据见表 $3 . \mathrm{Li}$ 等 ${ }^{[81]}$ 合成了三种新的 10-苯基- $10 H$-螺环 [ ${ }^{\prime} Y^{\circ}$ 定-9, $9^{\prime}$-芴]空穴传 输材料 CW3、CW4 和 CW5，总收率高达 $60 \%$. CW3 由 于分子间距离最小而显示出最高的导电性, 然而其较小 的分子尺寸导致较差的表面覆盖, 减少了空穴提取. CW5 由于存在较多叔丁基, 导致器件的电流较低. CW4 在表面覆盖和空间相互作用的 CW3 和 CW5 之间取得了 


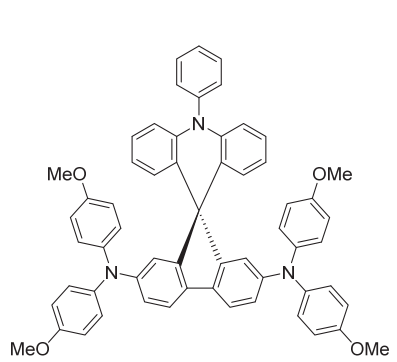

W 3

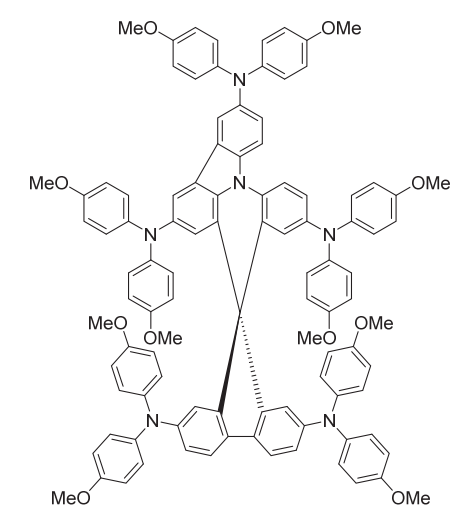

SCZF-5
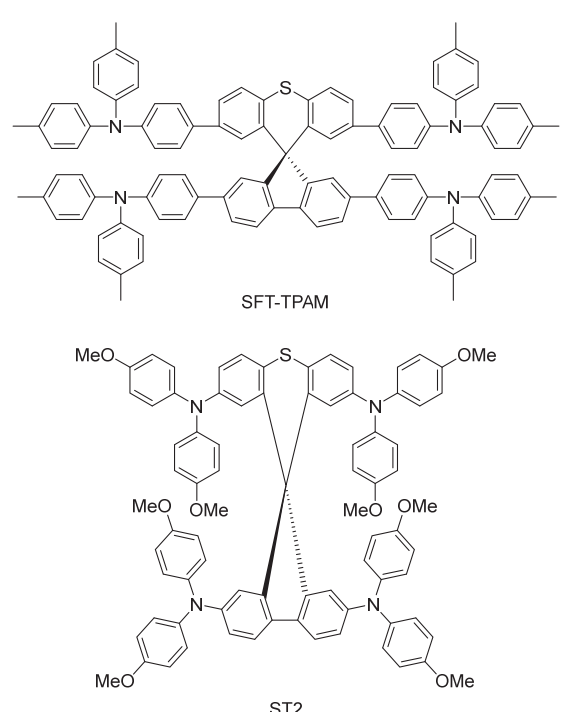
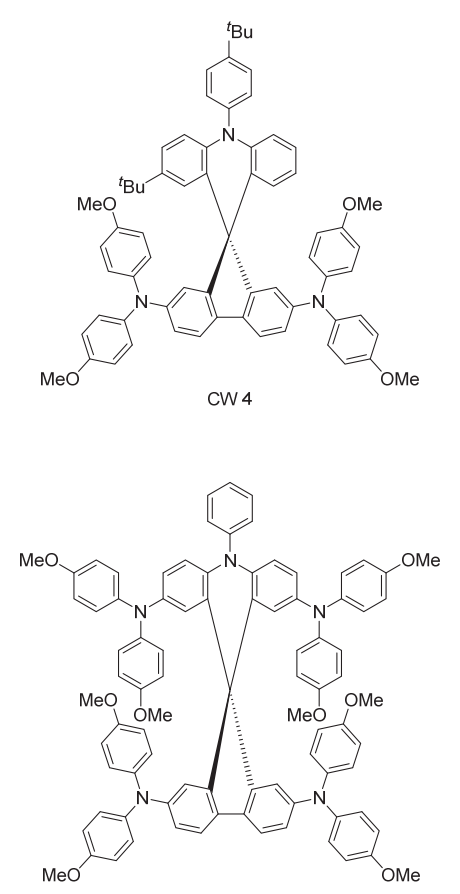

SAF-OMe
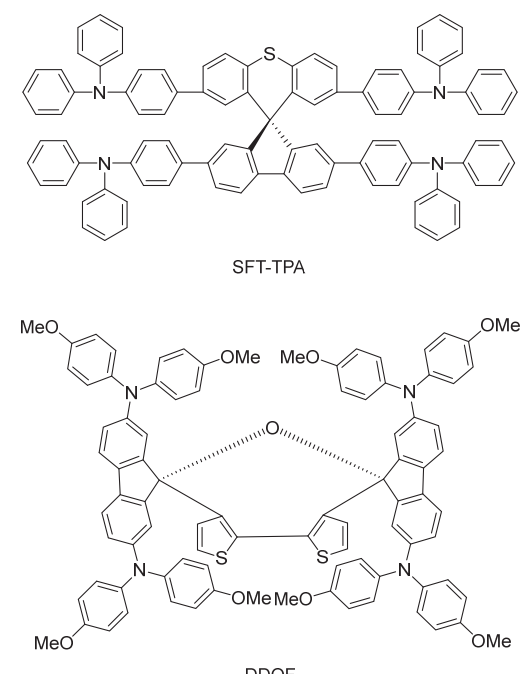
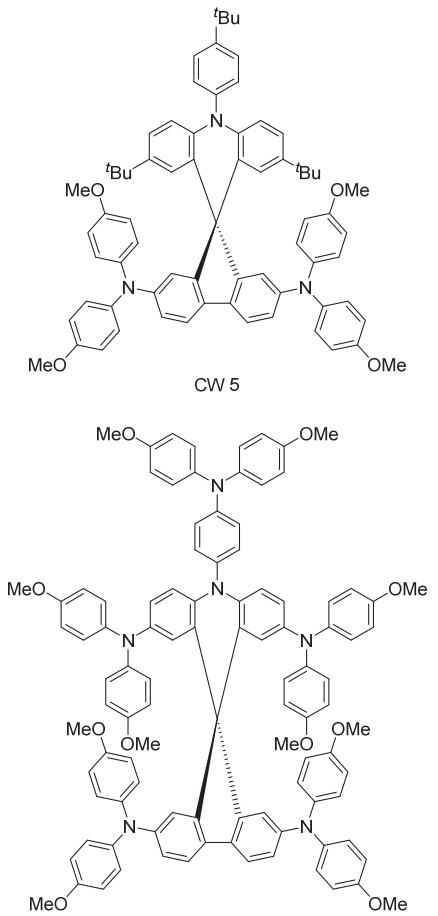

SAF-5

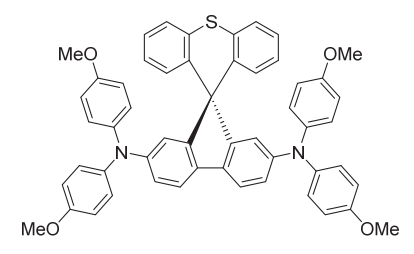

ST

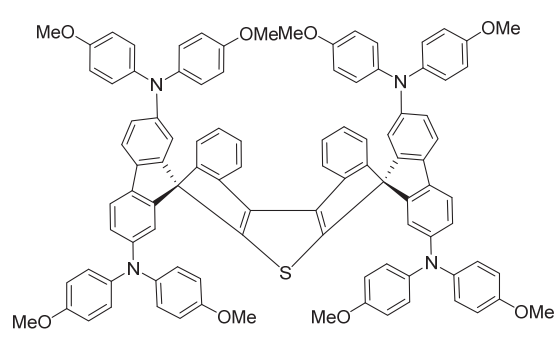

$\mathrm{G} 2(\mathrm{C} 102)$

图 14 含硫、氮的螺芳基芴衍生物的空穴传输材料

Figure 14 Sulfur and nitrogen containing spiro arylfluorene derivatives as hole transport materials in perovskite solar cells

平衡, $\mathrm{CW} 4$ 在采用钙钛矿层为 $\mathrm{CH}_{3} \mathrm{NH}_{3} \mathrm{PbI}_{3}$ 的器件时 $\mathrm{PCE}$ 达到了 $16.6 \%$. Wang 等 ${ }^{[82]}$ 制备的非掺杂 SAF-OMe 采用 $\mathrm{CH}_{3} \mathrm{NH}_{3} \mathrm{PbI}_{3-x} \mathrm{Cl}_{x}$ 为钙钛矿层时 $\mathrm{PCE}$ 为 $12.39 \%$, 甚 至可以与同条件下掺杂的 spiro-OMeTAD 器件(PCE: 14.84\%)相媲美. 此外, 掺杂后的 PCE 可达到 $16.73 \%$ (如 图 15). Zhu 等 ${ }^{[83]}$ 合成的 SAF-5 (PCE: $12.95 \% \pm 0.66 \%$ ), 虽然 PCE 不如 spiro-OMeTAD 的 $(18.11 \% \pm 0.65 \%)$ 高, 但 其衍生物 SCZF-5 在使用 $\mathrm{MAPbI}_{3}$ 为钙铁矿层的器件时, 获得了更好的耐久性和更高的效率(PCE：19.16\% 士 $0.64 \%)$.

\section{3 基于含硫螺环芳香骨架的 HTMs}

Deng 等 ${ }^{[8]}$ 通过引入较大的三维分子结构和杂原子
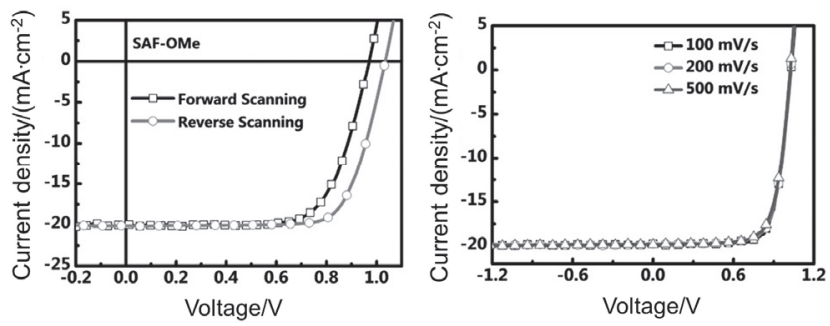

图 15 使用 SAF-OMe 的钙钣矿太阳能电池的稳定性. (a) 在无任何封 装的正向扫描模型和反向扫描模型 $\left(0.1 \mathrm{~V} \cdot \mathrm{s}^{-1}\right)$ 下测量的器件; (b) 在不 同扫描时间下测量的器件: 100、200 和 $500 \mathrm{~ms}^{[82]}$

Figure 15 Stability of perovskite cells using SAF-OMe. (a) Devices measured at forward scanning model and reverse scanning model $(0.1$ $\mathrm{V} \cdot \mathrm{s}^{-1}$ ) without any encapsulations; (b) devices measured with different scanning time: 100,200 and $500 \mathrm{~ms}^{[82]}$ 
表 3 含硫、氮的螺芳基荡衍生物的空穴传输材料在钻钛矿太阳能电池中的应用

Table 3 Application of sulfur and nitrogen containing spiro arylfluorene derivatives as hole transport materials in perovskite solar cells

\begin{tabular}{cccccccccc}
\hline HTMs & $\mathrm{HOMO} / \mathrm{eV}$ & $\mathrm{LUMO} / \mathrm{eV}$ & $\sigma /\left({\left.\mathrm{S} \bullet \mathrm{cm}^{-1}\right)}^{-1}\right.$ & $\mu_{\mathrm{h}} /\left(\mathrm{cm}^{2} \cdot \mathrm{V}^{-1} \cdot \mathrm{s}^{-1}\right)$ & $V_{\mathrm{oc}} / \mathrm{V}$ & $J_{\mathrm{sc}} /\left(\mathrm{mA} \cdot \mathrm{cm}^{-2}\right)$ & $F F$ & PCE/\% & Ref. \\
\hline CW3 & -4.92 & -1.89 & $5.92 \times 10^{-6}$ & $1.2 \times 10^{-4}$ & 0.99 & 16.49 & 67 & 10.94 & {$[81]$} \\
CW4 & -4.92 & -1.88 & $3.54 \times 10^{-6}$ & $5.8 \times 10^{-5}$ & 1.05 & 21.75 & 72 & 16.56 & {$[81]$} \\
CW5 & -4.93 & -1.89 & $3.09 \times 10^{-6}$ & $8.7 \times 10^{-5}$ & 1.01 & 15.39 & 70 & 10.76 & {$[81]$} \\
SAF-OMa $^{a}$ & -5.07 & -2.11 & - & $9.9 \times 10^{-4}$ & 0.97 & 20.59 & 62 & 17.39 & {$[82]$} \\
SAF-5 $^{a}$ & -5.02 & -2.05 & - & $1.73 \times 10^{-4}$ & 1.07 & 20.41 & 63 & 13.93 & {$[82]$} \\
SFT-TPAM $^{a}$ & -5.69 & -2.81 & - & - & 1.04 & 12.17 & 25 & 3.16 & {$[70]$} \\
SFT-TPA $^{a}$ & -5.71 & -2.78 & - & - & 0.68 & 11.32 & 37 & 2.85 & {$[70]$} \\
ST & -5.16 & -2.02 & - & $4.75 \times 10^{-5}$ & - & - & - & - & {$[84]$} \\
ST2 & -5.14 & -1.95 & - & $1.82 \times 10^{-4}$ & - & - & - & - & {$[84]$} \\
DDOF & -5.07 & -2.05 & - & - & 1.10 & 22.37 & 79 & 19.4 & {$[85]$} \\
G2 & -5.22 & -2.27 & $2.77 \times 10^{-4}$ & $3.58 \times 10^{-4}$ & 1.13 & 23.52 & 76 & 20.2 & {$[52,86]$} \\
\hline
\end{tabular}

${ }^{a}$ Undoped HTM.

(例如: S/O) 有效地提高了分子的稳定性，显著提高 PSCs 性能. 在合成的 ST 和 ST2 中, 由于硫原子被引入螺环 中心核, 硫原子的 $3 \mathrm{p}$ 轨道与苯环的 $\pi$ 轨道之间的弱相互 作用降低了分子的 HOMO 和 LUMO 能级. 另一方面, 引入的烷基提高了 $\mathrm{HOMO}$ 水平. 反观 Govindan 等[70]合 成的 SFT-TPA (PCE: 2.85\%) 和 SFT-TPAM (PCE: 3.16\%) (如图 16). 对比可以发现, 供电子基团甲基的引入对器 件效率的提升更为显著.

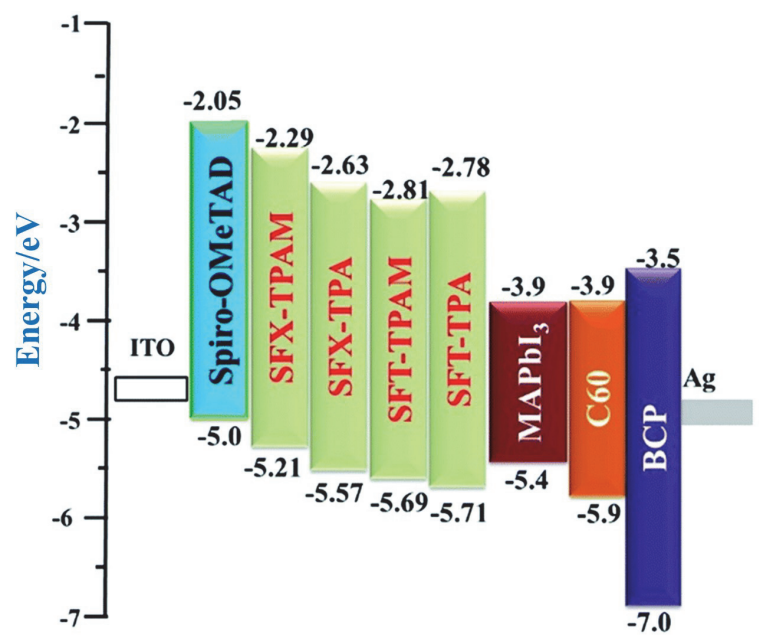

图 16 用于制备倒置钻针矿太阳能电池的 SFT-TPA 和 SFT-TPAM HOMO 能级及器件结构 ${ }^{[70]}$

Figure 16 SFT-TPA and SFT-TPAM frontier orbital energy levels and device structures for fabrication of inverted perovskite solar cells ${ }^{[70]}$

为了满足 HTMs 结构的设计多样化, 以进一步提高 其功能和性能的需要, 含硫的双螺环化合物成为人们研 究的新热点. 含有双噻吩结构的 DDOF 由 Rakstys 等 ${ }^{[85]}$ 合成, 虽然双噻吩单元已被证明与钙钛矿有额外的相互 作用, 但由于四个二甲氧基二苯胺连接在 $\mathrm{sp}^{3}$ 的氮原子 上形成四面体型结构产生了较大的空间位阻, 降低了结 晶性, 从而有利于形成均匀的薄膜形貌, 阻断电子复合, 阻挡钙钛矿表面的水分的侵蚀，同时可以抑制金纳米粒 子从电极上的迁移, 提高器件的性能, DDOF 在使用 $\left(\mathrm{FAPbI}_{3}\right)_{0.85}\left(\mathrm{MAPbBr}_{3}\right)_{0.15}$ 为钻钛矿吸光层时 $\mathrm{PCE}$ 达到了 19.4\%. Gao 等 ${ }^{[52]}$ 合成了一种基于含硫二螺环的 G2(与 C102 同构), 证明了使用含硫二螺环的 HTMs 用于高效
PSCs 的可行性. G2 不仅具有良好的成膜性能，还具有 与钙钛矿更匹配的 HOMO 能级, 其更高的迁移率、电导 率 ${ }^{886}$ 和稳定性也使得其在 $\left[\mathrm{HC}\left(\mathrm{NH}_{2}\right)_{2}\right]_{0.85}\left[\mathrm{CH}_{3} \mathrm{NH}_{3}\right]_{0.15^{-}}$ $\mathrm{Pb}\left[\mathrm{I}_{0.85} \mathrm{Br}_{0.15}\right]_{3}$ 为吸光层的器件达到了 $20.2 \%$ 的 PCE.

\section{6 结论与展望}

材料的效率与稳定性问题归根结底需要从结构角 度解决. 分析综述文献中的构效关系(图 17), 可以初步 归纳利用螺环芳烃构建 HTMs 分子的现有及潜在优势: （1）凭借立体构型，能以较小的几何空间集成更多的功

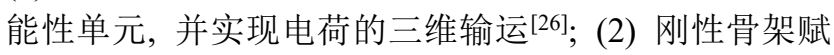
予分子优异的热稳定性, 进而提高薄膜质量及其形貌稳 定性 ${ }^{[59]}$; (3) 螺连接的二元、正交 $\pi$-体系, 促进分子内或 分子间电子耦合, 形成稳定、精细的能级结构, 提升材 料迁移率 ${ }^{[87-88]}$. 从螺二芴到螺[芴-9,9'-氧杂葱]、螺鲐啶、 螺硫杂葸的演化, 正驱动 HTMs 向低成本、高性能发展.

对未来在螺芳烃基础上进行功能化，设计、制备性 能更加优异的 HTMs 分子, 提出几点展望: (1) 螺结构两 侧的非对称功能化, 有望从结构对称性、电化学性质角 度, 优化分子堆积及能级性质, 获得形貌稳定、高迁移 率材料; (2) 功能单元的氟化或引入可与活性层金属离 子产生配位作用基团, 将提高空穴传输层的疏水性, 协

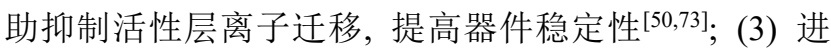
一步发展螺环芳烃的合成方法学，拓展分子结构设计空 间，同时降低材料制备成本 ${ }^{[89]}$.

\section{作者简介}

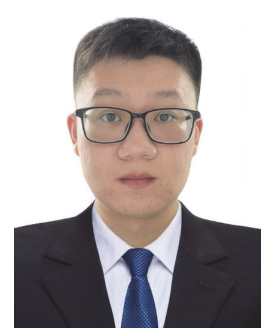

刘庆琳, 沈阳化工大学 2020 级硕士研究生, 研究方向为 有机半导体分子的合成与器件性能. 


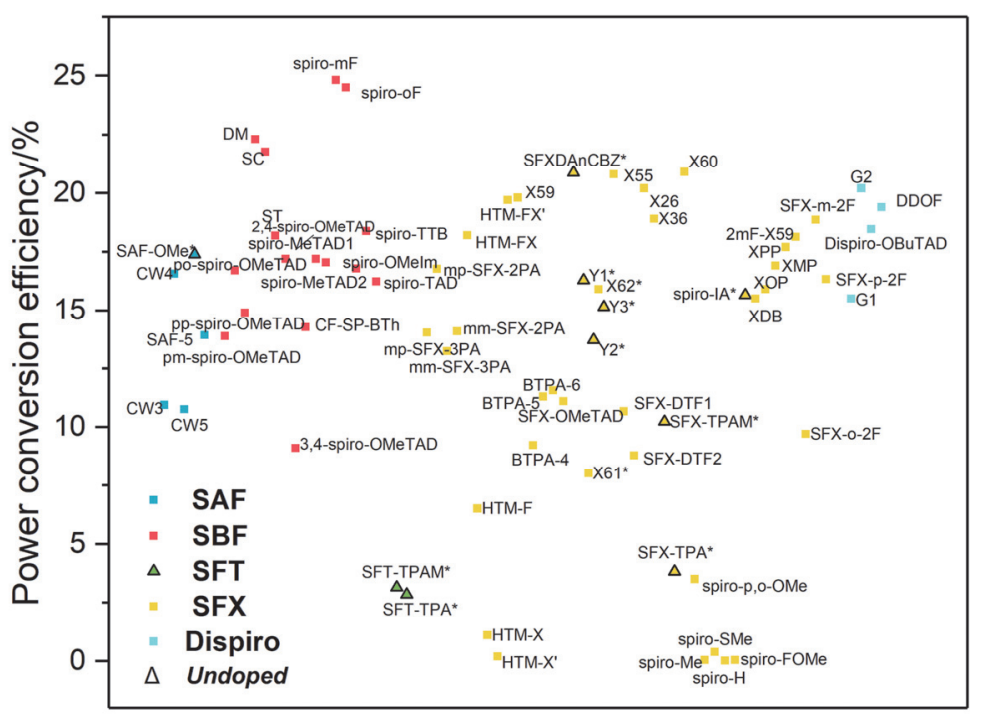

HTMs Based on Spiro-Core

图 17 不同类型螺芳基空穴传输材料的效率

Figure 17 Power conversion efficiency of different types of spiroaryl hole transport materials

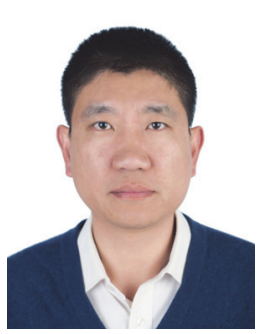

任保轶, 副教授, 2000 年于东北师范大学获应用化学学士 学位, 并在沈阳化工大学工作至今. 2012 年于东北大学获得工 学博士学位. 2016 年在劳伦斯伯克利国家实验室(Lawrence Berkeley National Laboratory)访学交流. 目前主要从事有机半 导体材料设计和器件性能研究.

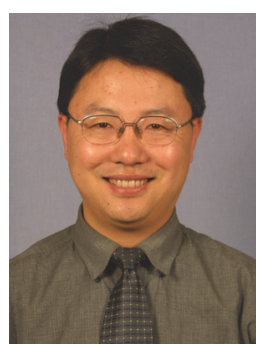

孙亚光, 博士, 沈阳化工大学教授, 现为辽宁省无机分子 基化学重点实验室主任. 主要从事 $\mathrm{MOFs} / \mathrm{COFs}$ 基微纳米晶体 的多相催化和光电器件研究.

\section{References}

[1] Celik, A. N.; Özgür, E. Renew. Sust. Energ. Rev. 2020, 134, 110344.

[2] Ju, C.-G.; Zhang, B.; Feng, Y.-Q. Prog. Chem. 2016, 28, 219 (in Chinese). (琚成功, 张宝, 冯亚青, 化学进展, 2016, 28, 219.)

[3] Kojima, A.; Teshima, K.; Shirai, Y.; Miyasaka, T. J. Am. Chem. Soc. 2009, 131,6050 .

[4] Best Research-Cell Efficiency Chart. https://www.nrel.gov/pv/ cell-efficiency.html.

[5] Im, J.-H.; Lee, C.-R.; Lee, J.-W.; Park, S.-W.; Park, N.-G. Nanoscale 2011, 3, 4088.

[6] Lee, M. M.; Teuscher, J.; Miyasaka, T.; Murakami, T. N.; Snaith, H.
J. Science 2012, 338, 643.

[7] Liu, M.; Johnston, M. B.; Snaith, H. J. Nature 2013, 501, 395 .

[8] Yang, W. S.; Noh, J. H.; Jeon, N. J.; Kim, Y. C.; Ryu, S.; Seo, J.; Seok, S. I. Science 2015, 348, 1234.

[9] Saliba, M.; Orlandi, S.; Matsui, T.; Aghazada, S.; Cavazzini, M.; Correa-Baena, J.-P.; Gao, P.; Scopelliti, R.; Mosconi, E.; Dahmen, K.-H.; De Angelis, F.; Abate, A.; Hagfeldt, A.; Pozzi, G.; Graetzel, M.; Nazeeruddin, M. K. Nat. Energy 2016, 1, 15017.

[10] Yang, W. S.; Park, B.-W.; Jung, E. H.; Jeon, N. J.; Kim, Y. C.; Lee, D. U.; Shin, S. S.; Seo, J.; Kim, E. K.; Noh, J. H.; Seok, S. I. Science 2017, 356, 1376.

[11] Jung, E. H.; Jeon, N. J.; Park, E. Y.; Moon, C. S.; Shin, T. J.; Yang, T.-Y.; Noh, J. H.; Seo, J. Nature 2019, 567, 511.

[12] Chiykowski, V. A.; Cao, Y.; Tan, H.; Tabor, D. P.; Sargent, E. H.; Aspuru-Guzik, A.; Berlinguette, C. P. Angew. Chem. Int. Ed. 2018 $57,15529$.

[13] Goldschmidt, V. M. Naturwissenschaften 1926, 14, 477.

[14] Eperon, G. E.; Paternò, G. M.; Sutton, R. J.; Zampetti, A.; Haghighirad, A. A.; Cacialli, F.; Snaith, H. J. J. Mater. Chem. A 2015, 3, 19688

[15] Petrus, M. L.; Schlipf, J.; Li, C.; Gujar, T. P.; Giesbrecht, N.; Mueller-Buschbaum, P.; Thelakkat, M.; Bein, T.; Huettner, S.; Docampo, P. Adv. Energy Mater. 2017, 7, 1700264.

[16] Chen, Y.-W.; Hu, T.; Tan, L.-C. Perovskite Solar Cells, Science Press, Beijing, 2020, pp. 16 17. (陈义旺, 胡婷, 谈利承, 钙钛矿 太阳能电池, 科学出版社, 北京, 2020, pp. 16 17.)

[17] Stranks, S. D.; Eperon, G. E.; Grancini, G.; Menelaou, C.; Alcocer, M. J. P.; Leijtens, T.; Herz, L. M.; Petrozza, A.; Snaith, H. J. Science 2013, 342, 341.

[18] Grätzel, M. Nat. Mater. 2014, 13, 838.

[19] Xiang, W.-C.; Pan, J.-Y.; Chen, Q. ACS Appl. Energy Mater. 2020, 3, 5977.

[20] Tsarev, S.; Luchkin, S. Y.; Stevenson, K. J.; Troshin, P. A. Synth. Met. 2020, 268, 116497.

[21] Ali, A.; Cha, M. J.; Kang, J. H.; Park, Y. J.; Seo, J. H.; Walker, B. Adv. Eng. Mater. 2020, 22, 2002422

[22] Ali, J.; Gao, P.; Zhou, G.-Q.; Li, Y.; Hao, T.-Y.; Song, J.-N.; Xu, J.-Q.; Qian, K.; Zhang, Q.-Z.; Zhu, L.; Zhang, M.; Wang, J.; Feng, W.; Hu, H.-L.; Liu, F. Adv. Electron. Mater. 2020, 6, 2000149.

[23] Ahmad, T.; Wilk, B.; Radicchi, E.; Fuentes Pineda, R.; Spinelli, P.; Herterich, J.; Castriotta, L. A.; Dasgupta, S.; Mosconi, E.; De Angelis, F.; Kohlstaedt, M.; Wuerfel, U.; Di Carlo, A.; Wojciechowski, K. Adv. Funct. Mater. 2020, 30, 2004357.

[24] Yang, D.; Yang, R.-X.; Wang, K.; Wu, C.-C.; Zhu, X.-J.; Feng, J.-S.; Ren, X.-D.; Fang, G.-J.; Priya, S.; Liu, S.-Z. Nat. Commun. 2018, 9 , 3239.

[25] Chiykowski, V. A. The design of hole-transport materials to stabilize the performance of perovskite solar cells, B.Sc., Queen's University, 


\section{Kingston, 2019}

[26] Kim, H.-S.; Lee, C.-R.; Im, J.-H.; Lee, K.-B.; Moehl, T.; Marchioro, A.; Moon, S.-J.; Humphry-Baker, R.; Yum, J.-H.; Moser, J. E.; Grätzel, M.; Park, N.-G. Sci. Rep. 2012, 2, 591.

[27] Urieta-Mora, J.; García-Benito, I.; Molina-Ontoria, A.; Martín, N. Chem. Soc. Rev. 2018, 47, 8541.

[28] Kim, G.-W.; Choi, H.; Kim, M.; Lee, J.; Son, S. Y.; Park, T. Adv. Energy Mater. 2020, 10, 1903403.

[29] Yin, C.-R.; Lu, J.-F.; Xu, Y.-C.; Yun, Y.-K.; Wang, K.; Li, J.-W.; Jiang, L.-C.; Sun, J.-S.; Scully, A. D.; Huang, F.-Z.; Zhong, J.; Wang, J.-P.; Cheng, Y.-B.; Qin, T.-S.; Huang, W. Adv. Energy Mater. 2018, 8, 1800538.

[30] Wang, Y.; Zhang, T.-Y.; Xu, F.; Li, Y.-H.; Zhao, Y.-X. Sol. RRL 2018, 2, 1700180.

[31] Shi, D.; Qin, X.; Li, Y.; He, Y.; Zhong, C.; Pan, J.; Dong, H.-L.; Xu, W.; Li, T.; Hu, W.-P.; Brédas, J.-L.; Bakr, O. M. Sci. Adv. 2016, 2, e1501491.

[32] Sheibani, E.; Yang, L.; Zhang, J.-B. Sol. RRL 2020, 4, 2000461

[33] Kasperski, A.; Szabelski, P. Copern. Lett. 2013, 4, 8

[34] Agarwala, P.; Kabra, D. J. Mater. Chem. A 2017, 5, 1348.

[35] Pudzich, R.; Fuhrmann-Lieker, T.; Salbeck, J. Adv. Polym. Sci. 2006, 199, 83.

[36] Saragi, T. P. I.; Spehr, T.; Siebert, A.; Fuhrmann-Lieker, T.; Salbeck, J. Chem. Rev. 2007, 107, 1011 .

[37] Shen, P.; Tang, Y.-H.; Jiang, S.-H.; Chen, H.-J.; Zheng, X.-Y.; Wang, X.-Y.; Bin, Z.; Tan, S.-T. Org. Electron. 2011, 12, 125.

[38] Bach, U.; Lupo, D.; Comte, P.; Moser, J. E.; Weissörtel, F.; Salbeck, J.; Spreitzer, H.; Grätzel, M. Nature 1998, 395, 583.

[39] Clarkson, R. G.; Gomberg, M. J. Am. Chem. Soc. 1930, 52, 2881.

[40] Pei, J.; Ni, J.; Zhou, X.-H.; Cao, X.-Y.; Lai, Y.-H. J. Org. Chem. 2002, 67, 4924.

[41] Tour, J. M.; Wu, R.; Schumm, J. S. J. Am. Chem. Soc. 1990, 112, 5662.

[42] Jeon, N. J.; Lee, H. G.; Kim, Y. C.; Seo, J.; Noh, J. H.; Lee, J.; Seok, S. I. J. Am. Chem. Soc. 2014, 136, 7837.

[43] Zhang, M.-D.; Zhao, D.-X.; Chen, L.; Pan, N.; Huang, C.-Y.; Cao, H.; Chen, M.-D. Sol. Energy Mater. Sol. Cells 2018, 176, 318.

[44] Jeon, N. J.; Na, H.; Jung, E. H.; Yang, T.-Y.; Lee, Y. G.; Kim, G.; Shin, H.-W.; Seok, S. I.; Lee, J.; Seo, J. Nat. Energy 2018, 3, 682.

[45] Deng, Z.-H.; He, M.-S.; Zhang, Y.; Ullah, F.; Ding, K.; Liang, J.-H.; Zhang, Z.-F.; Xu, H.; Qiu, Y.-K.; Xie, Z.; Shan, T.; Chen, Z.-H.; Zhong, H.-L.; Chen, C.-C. Chem. Mater. 2021, 33, 285.

[46] Miyasaka, T.; Kulkarni, A.; Kim, G. M.; Oz, S.; Jena, A. K. Adv. Energy Mater. 2020, 10, 1902500.

[47] Sallenave, X.; Shasti, M.; Anaraki, E. H.; Volyniuk, D.; Grazulevicius, J. V.; Zakeeruddin, S. M.; Mortezaali, A.; Grätzel, M.; Hagfeldt, A.; Sini, G. J. Mater. Chem. A $2020,8,8527$.

[48] Wang, C.; Hu, J.-L.; Li, C.-H.; Qiu, S.-D.; Liu, X.-H.; Zeng, L.-X.; Liu, C.-T.; Mai, Y.-H.; Guo, F. Sol. RRL 2020, 4, 1900389.

[49] Ameen, S.; Akhtar, M. S.; Nazim, M.; Kim, E.-B.; Nazeeruddin, M. K.; Shin, H.-S. Electrochim. Acta 2019, 319, 885.

[50] Jeong, M.; Choi, I. W.; Go, E. M.; Cho, Y.; Kim, M.; Lee, B.; Jeong, S.; Jo, Y.; Choi, H. W.; Lee, J.; Bae, J.-H.; Kwak, S. K.; Kim, D. S.; Yang, C. Science 2020, 369, 1615.

[51] Hajikhanmirzaei, L.; Shahroosvand, H.; Pashaei, B.; Monache, G. D.; Nazeeruddin, M. K.; Pilkington, M. J. Mater. Chem. C 2020, 8, 6221.

[52] Gao, K.; Xu, B.; Hong, C.-S.; Shi, X.-L.; Liu, H.-B.; Li, X.-S.; Xie, L.-H.; Jen, A. K. Y. Adv. Energy Mater. 2018, 8, 1800809.

[53] Yu, W.; Zhang, J.-H.; Wang, X.-C.; Liu, X.; Tu, D.-D.; Zhang, J.; Guo, X.; Li, C. Sol. RRL 2018, 2, 1800048.

[54] Chi, W.-J.; Li, Q.-S.; Li, Z.-S. Nanoscale 2016, 8, 6146.

[55] Liu, K.; Yao, Y.-H.; Wang, J.-Y.; Zhu, L.-F.; Sun, M.-L.; Ren, B.-Y.; Xie, L.-H.; Luo, Y.-H.; Meng, Q.-B.; Zhan, X.-W. Mater. Chem. Front. 2017, 1, 100.

[56] Xie, L.-H.; Liu, F.; Tang, C.; Hou, X.-Y.; Hua, Y.-R.; Fan, Q.-L.; Huang, W. Org. Lett. 2006, 8, 2787.

[57] Sun, M.-L.; Ou, C.-J.; Ren, B.-Y.; Xie, L.-H.; Zhao, X.-H.; Huang, W. Gen. Chem. 2020, 6, 190021.

[58] Bi, D.-Q.; Xu, B.; Gao, P.; Sun, L.; Graetzel, M.; Hagfeldt, A. Nano Energy 2016, 23, 138.

[59] Xu, B.; Bi, D.-Q.; Hua, Y.; Liu, P.; Cheng, M.; Graetzel, M.; Kloo, L.; Hagfeldt, A.; Sun, L.-C. Energy Environ. Sci. 2016, 9, 873.
[60] Xu, B.; Zhang, J.-B.; Hua, Y.; Liu, P.; Wang, L.-Q.; Ruan, C.-Q.; Li, Y.-Y.; Boschloo, G.; Johansson, E. M. J.; Kloo, L.; Hagfeldt, A.; Jen, A. K. Y.; Sun, L.-C. Chem 2017, 2, 676.

[61] Maciejczyk, M.; Ivaturi, A.; Robertson, N. J. Mater. Chem. A 2016, $4,4855$.

[62] Lee, D. Y.; Sivakumar, G.; Misra, M. R.; Seok, S. I. ACS Appl. Mater. Interfaces 2020, 12, 28246.

[63] Pham, H. D.; Yang, T. C.-J.; Jain, S. M.; Wilson, G. J.; Sonar, P. Adv. Energy Mater. 2020, 10, 1903326.

[64] Wu, G.-H.; Zhang, Y.-H.; Kaneko, R.; Kojima, Y.; Sugawa, K.; Chowdhury, T. H.; Islam, A.; Shen, Q.; Akhtaruzzaman, M.; Noda, T.; Otsuki, J. Sol. RRL 2017, 1, 1700096.

[65] Zhang, Y.; Wu, F.; Chen, L.; Zhang, F.-Y.; Ji, Y.; Shen, W.; Li, M.; Guo, Q.-X.; Su, W.; He, R.-X. Sol. Energy Mater. Sol. Cells 2020, $212,110534$.

[66] Zhang, Y.; Li, Y.-Y.; Chen, C.; Wang, L.; Zhang, J.-L. Org. Electron. 2017, 49, 255.

[67] Xu, B.-B.; Chakraborty, H.; Remsing, R. C.; Klein, M. L.; Ren, S.-Q. Adv. Mater. 2017, 29, 1605150.

[68] Wu, M.; Li, J.; Zhang, R.-Q.; Tian, X.; Han, Z.-X.; Lu, X.-Q.; Guo, K.-P.; Liu, Z.-K.; Wang, Z.-Q. Org. Lett. 2018, $20,780$.

[69] Zhang, J.-B.; Xu, B.; Yang, L.; Ruan, C.-Q.; Wang, L.-Q.; Liu, P.; Zhang, W.; Vlachopoulos, N.; Kloo, L.; Boschloo, G.; Sun, L.-C.; Hagfeldt, A.; Johansson, E. M. J. Adv. Energy Mater. 2018, 8 , 1701209 .

[70] Govindan, V.; Yang, K.-C.; Fu, Y.-S.; Wu, C.-G. New J. Chem. 2018, $42,7332$.

[71] Abdellah, I. M.; Chowdhury, T. H.; Lee, J.-J.; Islam, A.; Nazeeruddin, M. K.; Gräetzel, M.; El-Shafei, A. Sustain. Energy Fuels 2021, 5, 199.

[72] Wang, Y.; Liao, Q.-G.; Chen, J.-H.; Huang, W.; Zhuang, X.-M.; Tang, Y.-M.; Li, B.-L.; Yao, X.-Y.; Feng, X.-Y.; Zhang, X.-H.; Su, M.-Y.; He, Z.-B.; Marks, T. J.; Facchetti, A.; Guo, X.-G. J. Am. Chem. Soc. 2020, 142, 16632.

[73] Xu, B.; Zhu, Z.-L.; Zhang, J.-B.; Liu, H.-B.; Chueh, C.-C.; Li, X.-S.; Jen, A. K. Y. Adv. Energy Mater. 2017, 7, 1700683

[74] Wang, L.-Q.; Zhang, J.-B.; Liu, P.; Xu, B.; Zhang, B.-B.; Chen, H.; Inge, A. K.; Li, Y. Y.; Wang, H. X.; Kloo, L.; Sun, L.-C. Chem. Commun. 2018, 54, 9571.

[75] Lee, J.; Malekshahi Byranvand, M.; Kang, G.; Son, S. Y.; Song, S.; Kim, G.-W.; Park, T. J. Am. Chem. Soc. 2017, 139, 12175.

[76] Guo, K.; Wu, M.; Yang, S.; Wang, Z.; Li, J.; Liang, X.; Zhang, F.; Liu, Z.; Wang, Z. Sol. RRL 2019, 3, 1800352.

[77] Yang, S.-M.; Zhao, H.; Wu, M.; Yuan, S.-H.; Han, Y.; Liu, Z.-K.; Guo, K.-P.; Liu, S.-Z.; Yang, S.; Zhao, H.; Yuan, S.; Han, Y.; Liu, Z.; Liu, S.; Wu, M.; Guo, K. Sol. Energy Mater. Sol. Cells 2019, 201, 110052 .

[78] Li, Z.-N.; Yun, Y.-K.; Huang, H.-Y.; Ding, Z.-C.; Li, X.-W.; Zhao, B.-M.; Huang, W. J. Energy Chem. 2020, 57, 341.

[79] Li, Y.-C.; Wang, Z.-H.; Li, X.-L.; Xie, G.-Z.; Chen, D.-C.; Wang, Y.-F.; Lo, C.-C.; Lien, A.; Peng, J.-B.; Cao, Y.; Su, S.-J. Chem. Mater. 2015, 27, 1100 .

[80] Jiang, Z.-Q.; Liu, Z.-Y.; Yang, C.-L.; Zhong, C.; Qin, J.-G.; Yu, G.; Liu, Y.-Q. Adv. Funct. Mater. 2009, 19, 3987.

[81] Li, M.-H.; Hsu, C.-W.; Shen, P.-S.; Cheng, H.-M.; Chi, Y.; Chen, P.; Guo, T.-F. Chem. Commun. 2015, 51, 15518

[82] Wang, Y.-K.; Yuan, Z.-C.; Shi, G.-Z.; Li, Y.-X.; Li, Q.; Hui, F.; Sun, B.-Q.; Jiang, Z.-Q.; Liao, L.-S. Adv. Funct. Mater. 2016, 26, 1375.

[83] Zhu, X.-D.; Ma, X.-J.; Wang, Y.-K.; Li, Y.; Gao, C.-H.; Wang, Z.-K.; Jiang, Z.-Q.; Liao, L.-S. Adv. Funct. Mater. 2019, 29, 1807094.

[84] Deng, J.-D.; Hu, W.-X.; Shen, W.; Li, M.; He, R.-X. Phys. Chem. Chem. Phys. 2019, 21, 1235.

[85] Rakstys, K.; Paek, S.; Sohail, M.; Gao, P.; Cho, K. T.; Gratia, P.; Lee, Y.; Dahmen, K. H.; Nazeeruddin, M. K. J. Mater. Chem. A 2016, 4, 18259

[86] Cai, B.; Yang, X.-C.; Wang, H.-X.; Wang, W.-H.; An, J.-C.; Sun, L.-C. J. Energy Chem. 2019, 32, 152.

[87] Yavuz, I.; Houk, K. N. J. Phys. Chem. C 2017, 121, 993.

[88] Hamada, H.; Itabashi, Y.; Shang, R.; Nakamura, E. J. Am. Chem. Soc. 2020, 142, 2059.

[89] Liu, H.; Liu, Z.-W.; Li, G.-G.; Huang, H.-N.; Zhou, C.-J.; Wang, Z.-M.; Yang, C.-L. Angew. Chem. Int. Ed. 2021, 60, 12376. 